\title{
Screening and management of atrial fibrillation in primary care
}

\author{
Shiva P Ponamgi, ${ }^{1}$ Konstantinos C Siontis, ${ }^{2}$ David R Rushlow, ${ }^{3}$ Jonathan Graff-Radford, ${ }^{4}$ \\ Victor Montori, ${ }^{5,6}$ Peter A Noseworthy ${ }^{2,6}$
}

Check for updates

${ }^{1}$ Division of Hospital Internal Medicine, Mayo Clinic Health System, Austin, MN, USA

${ }^{2}$ Department of Cardiovascular Medicine, Mayo Clinic,

Rochester, MN, USA

${ }^{3}$ Department of Family

Medicine, Mayo Clinic,

Rochester, MN 55905, USA

${ }^{4}$ Department of Neurology,

Mayo Clinic, Rochester, MN

USA

${ }^{5}$ Division of Endocrinology, Mayo Clinic, Rochester, MN, USA

${ }^{6}$ Knowledge and Evaluation Research Unit, Mayo Clinic, Rochester, MN, USA

Correspondence to:

PA Noseworthy

noseworthy.peter@mayo.edu

Cite this as: BMJ 2021;372:mn379 http://dx.doi.org/10.1136/bmi.mn379

Series explanation: State of the Art Reviews are commissioned on the basis of their relevance to academics and specialists in the US and internationally. For this reason they are written predominantly by US authors.

Additional material is published online only. To view please visit the journal online.

\begin{abstract}
Atrial fibrillation is a common chronic disease seen in primary care offices, emergency departments, inpatient hospital services, and many subspecialty practices. Atrial fibrillation care is complicated and multifaceted, and, at various points, clinicians may see it as a consequence and cause of multi-morbidity, as a silent driver of stroke risk, as a bellwether of an acute medical illness, or as a primary rhythm disturbance that requires targeted treatment. Primary care physicians in particular must navigate these priorities, perspectives, and resources to meet the needs of individual patients. This includes judicious use of diagnostic testing, thoughtful use of novel therapeutic agents and procedures, and providing access to subspecialty expertise. This review explores the epidemiology, screening, and risk assessment of atrial fibrillation, as well as management of its symptoms (rate and various rhythm control options) and stroke risk (anticoagulation and other treatments), and offers a model for the integration of the components of atrial fibrillation care.
\end{abstract}

\section{Introduction}

Atrial fibrillation, a chaotic heart rhythm characterized by an irregular and often rapid heart rate, is a common arrhythmia. ${ }^{1}$ Its incidence and public health impact are growing as a result of the increasing multi-morbidity and longevity of the population and increasing ease of diagnosis. ${ }^{2-5}$ Despite increasing availability of methods for diagnosis, much of atrial fibrillation goes undetected and under-diagnosed. ${ }^{67}$

Although some patients with atrial fibrillation have no symptoms, ${ }^{78}$ many experience bothersome palpitations, shortness of breath, or exercise intolerance. A subset develop complications including thromboembolism/stroke, ${ }^{9-12}$ heart failure, ${ }^{13}$ or cognitive impairment, ${ }^{14}$ and atrial fibrillation is associated with a nearly twofold excess risk of all cause mortality. ${ }^{15}$ Prevalence of atrial fibrillation increases with age, and it commonly coexists with other comorbidities that are typically cared for in a primary care setting, such as hypertension, sleep apnea, and obesity.

No definitive cure for atrial fibrillation exists, so its management focuses on four main pillars: efforts to correct risk factors, lifestyle interventions, and comorbidities; rate control strategies; rhythm control strategies; and reduction of stroke risk (fig 1). Specific therapies can range from simple medications to invasive procedures, including catheter ablation, pacemaker implantation, left atrial appendage occlusion, and even cardiac surgery. Navigating this wide array of options in a complex and diverse population requires active patient engagement in decision making and careful consideration of context and preferences. Herein, we review the current state of screening, diagnosis, risk stratification, and management for atrial fibrillation.

\section{Sources and selection criteria}

We identified literature through a search of PubMed until January 2020 for keywords including "atrial fibrillation AND epidemiology" OR "atrial fibrillation AND natural history" OR "atrial fibrillation AND stroke risk" OR "CHA DS -VASc" OR "CHADS," OR "HAS-BLED” OR "atrial fibrillation AND warfarin" OR "atrial fibrillation AND direct oral anticoagulants" OR "atrial fibrillation AND novel oral anticoagulants" OR "atrial fibrillation AND apixaban" OR "atrial fibrillation AND dabigatran" OR "atrial fibrillation AND rivaroxaban" OR "atrial fibrillation AND edoxaban" OR "atrial fibrillation AND screening" OR "atrial fibrillation AND treatment". Owing to the vast number of studies in the search results $(68824$ results), we prioritized studies that were randomized controlled trials (RCTs), systematic reviews, or metaanalyses to gather the strongest level of evidence for each topic being discussed (5396 results) and then limited the results to studies in humans that were published in English in the past 10 years (3148 results). We also included relevant observational 


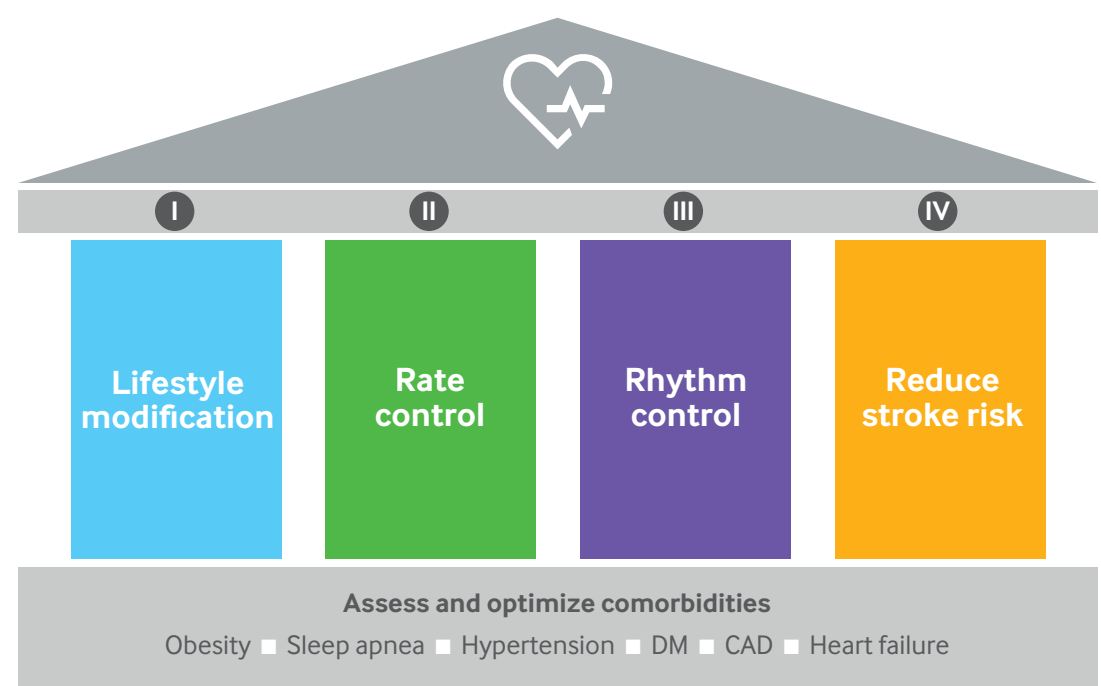

Fig 1 | Pillars of atrial fibrillation management as described in American Heart Association scientific statement outlining lifestyle and risk factor modification for reduction of atrial fibrillation. ${ }^{16} \mathrm{CAD}=$ coronary artery disease; $\mathrm{DM}=$ diabetes mellitus

studies that were published in journals that are clinically focused and have a high impact factor to present a comprehensive outlook. We reviewed abstracts of all the studies to categorize the relevant ones for inclusion and discarded studies irrelevant to our topic. We also searched the references of included studies for further relevant studies. We prioritized recent studies with larger sample sizes over older and smaller studies. We included older studies only if important and pertinent to the topic being discussed or if recent research in that area was unavailable.

\section{Epidemiology}

Atrial fibrillation is estimated to affect more than 30 million people globally. ${ }^{1}$ The incidence and prevalence of atrial fibrillation have increased steadily over the past 20 years, and it will doubtless present a growing public health challenge. ${ }^{2}$ The increased prevalence of atrial fibrillation may be due to increasing multi-morbidity and longevity, as well as the widespread availability of more sensitive rhythm monitoring methods that allow earlier detection of arrhythmia. $^{3-5}$ Furthermore, this apparent increase in prevalence may be an underestimate, as much of atrial fibrillation is asymptomatic and undiagnosed. ${ }^{6}$ In a community based cohort with manually validated new diagnoses of atrial fibrillation, one in three patients had no symptoms whatsoever at the time of coincidental detection of atrial fibrillation by electrocardiography performed for a different reason. $^{7}$

Several non-modifiable and modifiable risk factors are recognized as playing a role in atrial fibrillation. The incidence and prevalence of atrial fibrillation increases with age and is higher in men than in women. ${ }^{17-20}$ Although the overall prevalence of atrial fibrillation in men is double that in women, among older adults more women than men have atrial fibrillation owing to the longer longevity of women. ${ }^{21}$ A familial predisposition to atrial fibrillation is also recognized, but in most cases atrial fibrillation is not a monogenetic disorder.

Structural, functional, and electrophysiological changes resulting from a complex interplay of risk factors are thought to be responsible for the initiation, progression, and maintenance of atrial fibrillation. ${ }^{22}$ In many patients, these changes may include left ventricular hypertrophy, diastolic dysfunction, left atrial enlargement, left atrial fibrosis, left atrial stiffness, and autonomic dysfunction. In other cases of atrial fibrillation especially in young patients, no identifiable risk factors may exist, suggesting a possible genetic predisposition. ${ }^{23-25}$ Regardless, atrial fibrillation can by itself sustain and further promote atrial, ventricular, and systemic structural and functional alterations. Thus, breaking this vicious cycle requires targeting of both the risk factors for atrial fibrillation and the atrial fibrillation itself.

\section{Natural history of atrial fibrillation}

The natural history of atrial fibrillation is highly variable but tends to follow a progression from a paroxysmal pattern to a more persistent and even chronic pattern over time. However, as much of atrial fibrillation may result in no symptoms, the natural history of subclinical atrial fibrillation and the true burden of the arrhythmia are poorly characterized. ${ }^{26-28}$ In experimental animal models, the observation that structural and electrophysiological substrate changes worsen as a function of the chronicity of the arrhythmia ("atrial fibrillation begets atrial fibrillation") has led to the prevailing hypothesis that atrial fibrillation progresses to an increasingly permanent form over time. ${ }^{29-31}$ Atrial fibrillation is classified as "paroxysmal" if episodes terminate spontaneously or after targeted intervention within seven days, whereas atrial fibrillation lasting more than seven days without termination is considered "persistent" and often requires electrical or pharmacological 
cardioversion for termination. Atrial fibrillation that persists continuously for longer than a year is termed "longstanding persistent atrial fibrillation." Finally, when the patient and clinician decide not to pursue any attempt to restore normal rhythm, atrial fibrillation is considered "permanent." The rapidity of progression from a paroxysmal to more persistent or permanent arrhythmia varies and is affected by the control of comorbid/underlying conditions, as well as other, as yet unidentified factors. Some evidence is increasingly suggesting that early treatment may improve clinical outcomes. ${ }^{32} 33$

Atrial fibrillation is so common in older populations that it can seem to be an inevitable consequence of aging. However, more than $50 \%$ of the incidence of atrial fibrillation in some populations is thought to be the result of suboptimal risk factor control. ${ }^{34}$ Like many chronic conditions, atrial fibrillation is highly related to common comorbidities, and lifestyle interventions are the backbone of preventive care (fig 2). Although some risk factors for atrial fibrillation are not modifiable (age, ${ }^{17} 18$ male sex, ${ }^{19} 20$ or family history, for instance), patients should be aware that they can reduce the risk and burden of atrial fibrillation through lifestyle interventions. ${ }^{36} 37$ The Framingham Heart Study identified hypertension, congestive heart failure, coronary artery disease, and diabetes mellitus as risk factors for the development of atrial fibrillation. ${ }^{20}$ Obesity, obstructive sleep apnea, and other lifestyle factors such as chronic endurance training have also been associated with increased risk of atrial fibrillation. ${ }^{38-40}$ Comorbidities such as hypertension, valvular heart disease, chronic obstructive pulmonary disease, and cerebrovascular disease are known to predict progression of atrial fibrillation and poor response to catheter ablation. ${ }^{41} 42$ These risk factors should also be considered as targets for prevention of atrial fibrillation in the primary care setting (fig 2).

\section{Screening for atrial fibrillation}

Screening for indolent or asymptomatic diseases that are common but treatable is central to the mission of primary care. To be valuable, a screening test must have sufficient precision, and effective and safe downstream interventions that can improve outcomes must exist. Whether screening for atrial fibrillation fulfils these criteria is controversial, however, and current guidelines and many professional societies do not recommend routine screening in primary care. For instance, the 2019 UK National Screening Committee posed a series of criteria that would need to be established to justify screening and then, after performing an exhaustive evidence review around each criterion, concluded that many factors remain "uncertain" so that screening is not recommended at this time. ${ }^{43}$ The criteria they explored included the relative risk of stroke based on type of atrial fibrillation, evidence for a benefit of treating atrial fibrillation detected by screening, the reported accuracy of screening tests for atrial fibrillation, the availability of RCT level evidence of

\section{Example of aggressive risk factor management protocol}

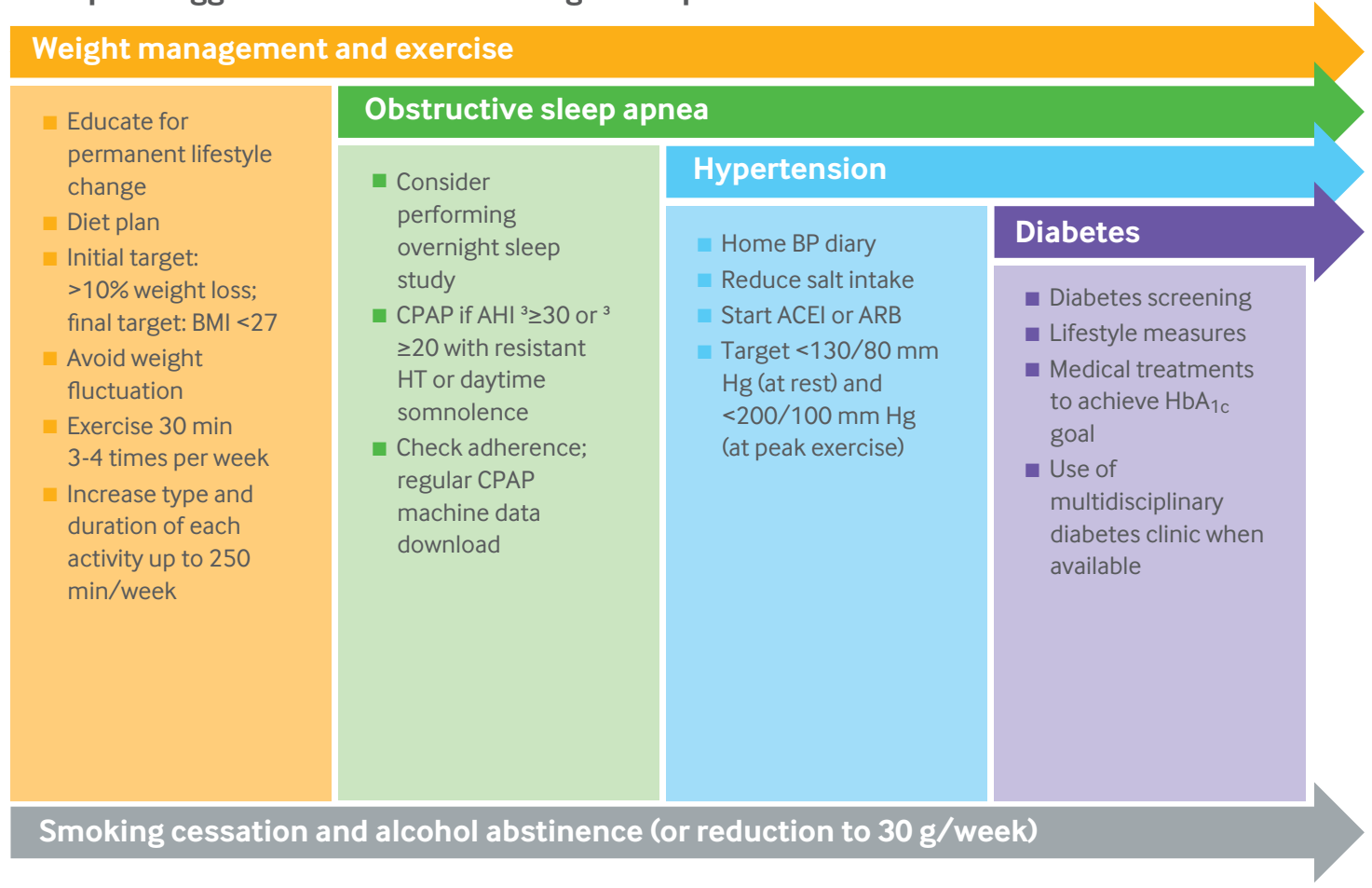

Fig 2 | Components of risk factor modification in primary and secondary prevention of atrial fibrillation. ACEI=angiotensin converting enzyme

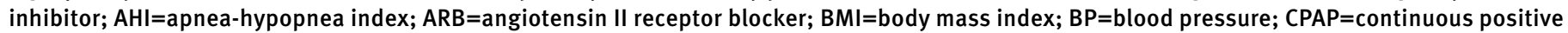
airway pressure; $\mathrm{HbA}_{1 \mathrm{c}}=$ hemoglobin $\mathrm{A}_{1 \mathrm{c}} ; \mathrm{HT}=$ hypertension. Adapted from Lau et a $\mathrm{a}^{135}$ 
a benefit of screening, cost effectiveness, and clinical infrastructure of optimal treatment. Similarly, the United States Preventive Services Task Force has concluded that the current evidence is insufficient to assess the balance of benefits and harms of screening for atrial fibrillation with electrocardiography, ${ }^{44}$ and the 2014 National Institute for Health and Care Excellence atrial fibrillation guidelines refer to pulse palpation as the only recommended screening assessment for atrial fibrillation, but only in patients with symptoms. ${ }^{45}$

Why then does this remain controversial? Data are certainly mixed, and the role for targeted screening of patients at risk may evolve over time as rhythm monitoring technologies are further refined and as the evidence base is further developed. ${ }^{46-48}$ Among patients with a cryptogenic stroke who undergo 30 day rhythm monitoring, as many as about $15 \%$ are found to have previously undiagnosed paroxysmal atrial fibrillation. ${ }^{49}$ The observational STROKESTOP study in Sweden showed that population based electrocardiographic screening of people aged 75 years or older was associated with a reduction in the occurrence of ischemic strokes at five years of followup..$^{50}$ In the area where screening for atrial fibrillation was implemented, ischemic stroke declined from 14.5 to 9.1 per 1000 person years $(\mathrm{P}=0.003)$, whereas the incidence did not change significantly in the control area (from 12.7 to 11.2 per 1000 person years; $\mathrm{P}=0.31$ ).

A desire to prevent strokes, coupled with the exponential growth of mobile and wearable rhythm monitoring technologies, has led to a heightened interest in the role of screening general populations for atrial fibrillation. ${ }^{51}$ Possible low cost and convenient screening methods include pulse palpation, ${ }^{52}$ automated blood pressure monitors, single lead or multi-lead electrocardiography devices, ${ }^{53-55}$ insertable monitors, ${ }^{5657}$ and even pulse photoplethysmography $^{58}$ or electrocardiography based smartwatch applications. Most notably, in the recent Apple Heart Study, the largest pragmatic evaluation of atrial fibrillation screening in a general population using a smartwatch enabled pulse photoplethysmography technology, $0.52 \%$ of participants received notifications of possible atrial fibrillation over an average of more than three months of monitoring. ${ }^{59}$ In about a third of these people, atrial fibrillation was later confirmed by week long patch electrocardiography monitoring. This suggests that although mass screening of unselected populations is feasible with current technologies, the yield of such an approach is low, and the clinical impact is uncertain. One should also weigh in the drawbacks of monitoring and diagnosis related anxiety, as well as the unclear indications for treatment of atrial fibrillation detected by long term rhythm monitoring. For example, the effect of the duration and burden of atrial fibrillation on treatment decisions is largely unknown, and further population based studies are needed to evaluate the value of smartwatches in long term screening for atrial fibrillation. ${ }^{58}$
More than a dozen ongoing prospective studies are examining the role of screening for atrial fibrillation, and this growing body of evidence will certainly inform future recommendations. ${ }^{60}$ For now, however, we acknowledge that although screening can detect asymptomatic atrial fibrillation, the downstream benefit of widespread implementation of screening in unselected populations is unproven. ${ }^{61}$

\section{Risk assessments} $\mathrm{CHA}_{2} \mathrm{DS}_{2}$-VASc

Identifying patients with atrial fibrillation who are at sufficient risk of cardioembolic stroke to warrant systemic anticoagulation is a clinical and research priority. Nearly 20 years ago, before the introduction of direct oral anticoagulants (DOACs), the CHADS scoring system was developed and validated. ${ }^{12}$ The system scores 1 point each for recent exacerbation of congestive heart failure, history of hypertension, age 75 years or older, and type 2 diabetes mellitus and 2 points for history of previous transient ischemic attack or stroke. Although this scoring system was rapidly adopted in practice, the overall performance is modest with an area under the curve typically in the 0.65-0.7 range. The scoring system also does not account for potentially powerful risk factors such as sex and underlying vascular disease, and it classifies a large proportion of patients in an intermediate risk category. $^{62}$

The risk stratification scheme was subsequently refined as the $\mathrm{CHA}_{2} \mathrm{DS}_{2}$-VASc score, ${ }^{63}$ which includes three additional factors: female sex, age 65-74 years, and vascular disease. The $\mathrm{CHA}_{2} \mathrm{DS}_{2}-\mathrm{VASc}$ score delineates the following risk categories for thromboembolism and recommended treatment approaches based on the 2014 American Heart Association/American College of Cardiology/ Heart Rhythm Society (AHA/ACC/HRS) atrial fibrillation guideline ${ }^{64}$ : $0=$ low risk (annual risk $0.3 \%$; anticoagulation generally not recommended), 1=low-moderate risk (annual risk 0.9\%; consider anticoagulant), and $\geq 2=$ moderate-high risk (annual risk $>2.9 \%$; anticoagulation recommended). The most valuable aspect of this newer scoring system is that it can identify people in the lowest risk category (score $=0$ ) as having a very low risk of stroke, and clinicians can be more confident in not offering anticoagulation for this group. However, the proportion of patients falling into this category is small $(<10 \%)$ and as many as $80 \%$ of the total atrial fibrillation population are categorized as at least intermediate risk (score of 2 or higher), ${ }^{65}$ resulting in a recommendation to anticoagulate a large majority of atrial fibrillation patients on the basis of the 2014 AHA/ACC/HRS atrial fibrillation guideline. ${ }^{64}$ An analysis suggested that this guideline's recommendation for use of the $\mathrm{CHA}_{2} \mathrm{DS}_{2}$-VASc and corresponding treatment thresholds resulted in an increase in the overall proportion of atrial fibrillation patients recommended for oral anticoagulation from $71.8 \%$ to $90.8 \%$ in the US. ${ }^{66}$ This corresponds to an increase in the number of patients recommended 
for anticoagulation from an estimated 3.7 million to 4.7 million. Furthermore, the overall discriminating performance of this scoring system is only marginally improved over the $\mathrm{CHADS}_{2}$ score, with areas under the curve typically estimated in the 0.68-0.7 range. The overall modest performance of these scoring systems, as well as the fact that they result in a recommendation to anticoagulate most patients (many of whom do not go on to have a stroke), particularly given the cost of the newer agents, has led many people to call for newer risk stratifications schemes, developed without influence of industry partners who could benefit from broad indications for anticoagulation.

\section{HAS-BLED}

Patients treated with anticoagulants are at increased risk of bleeding on treatment, which has also prompted the development of scoring systems to quantify bleeding risk. Although many such scoring systems have been developed, the HAS-BLED score has gained popularity and widespread adoption owing to its ease of use and accuracy in predicting bleeding risk in patients on anticoagulation. ${ }^{67-70}$ The HAS-BLED compiles risk factors including hypertension, renal disease, liver disease, stroke history, previous bleeding or predisposition to bleeding, labile international normalized ratio (INR), age above 65 years, medications predisposing to bleeding, and alcohol use (1 point each). The score can be used in patients not taking a vitamin $\mathrm{K}$ antagonist (VKA), but the variable for a labile INR is omitted from the calculation. ${ }^{68}$ According to the HASBLED score, atrial fibrillation patients are subdivided into three risk categories, in which a score of 0 indicates low risk, 1-2 indicates moderate risk, and 3 or higher indicates high risk. Various validation studies have examined HAS-BLED in predicting bleeding risk while on anticoagulation (both VKA and non-VKA anticoagulants), taking aspirin, or without any antithrombotic therapy. HAS-BLED is also the only score shown to be predictive of intracranial hemorrhage. The HAS-BLED score has also been validated in non-atrial fibrillation populations, including those with venous thromboembolism, ${ }^{71}$ acute coronary syndrome, or percutaneous coronary interventions and those undergoing anticoagulant bridging therapy. ${ }^{72}$

\section{Clinical application of risk assessments}

Current guidelines recommend the $\mathrm{CHA}_{2} \mathrm{DS}_{2}$-VASc scoring system, ${ }^{6373}$ which aggregates common risk factors to estimate a patient's risk and guide treatment decisions. This risk stratification approach does not apply to atrial fibrillation patients with severe mitral stenosis, mechanical valve prostheses, known atrial thrombus, hypertrophic or amyloid cardiomyopathy, or congenital heart disease. In these situations, anticoagulation is generally recommended in all patients with atrial fibrillation.

Clinicians and patients must frame decisions about anticoagulation in terms of how it will affect daily routines, hobbies, and work; how much it will cost and what demands it will make it on the patient's time; and the potential bleeding risk. Although the HAS-BLED score is the most widely accepted system to estimate bleeding risk, ${ }^{67-70}$ a high HAS-BLED score by itself is not a reason to withhold anticoagulation as risks for bleeding and stroke usually correlate. Patients with a high HAS-BLED score include those who may derive even greater net clinical benefit from anticoagulation owing to its effect on reduction of stroke risk. Instead of identifying patients who should not be anticoagulated, the HAS-BLED score should be used to flag those potentially at risk of bleeding who may warrant particularly careful monitoring and follow-up. Also, HAS-BLED draws attention to well established potentially reversible risk factors for bleeding, such as uncontrolled hypertension, labile INR, concomitant use of aspirin/non-steroidal antiinflammatory drugs, or alcohol excess.

The HAS-BLED score may underestimate bleeding risk in a subset of atrial fibrillation patients. Several conditions present a challenge in decision making, including chronic subdural hematoma, cerebral vascular malformations, gastrointestinal conditions that predispose to bleeding and may be difficult to treat (Crohn's disease, angiodysplasia), and hematological disorders of coagulation. Cerebral amyloid angiopathy (CAA), which involves $\beta$-amyloid deposition in cerebral blood vessels, is especially relevant in older people with atrial fibrillation and is a common cause of anticoagulant related intracranial hemorrhage. ${ }^{74}$ One meta-analysis estimated a $7.4 \%$ annual risk of CAA related recurrent intracranial hemorrhage, comparable in many older atrial fibrillation patients to the risk of ischemic stroke if untreated. $^{75}$

Clinically, CAA most often manifests with lobar hemorrhage but can also be detected in patients without symptoms with hemosiderin sensitive magnetic resonance imaging (MRI) sequences. As the HAS-BLED score does not account for such asymptomatic MRI lesions, the score may underestimate bleeding risk in this population. ${ }^{76}$ Both CAA and atrial fibrillation increase significantly with age, and people may undergo brain MRIs for a variety of indications; therefore, clinicians are more commonly encountering patients with both atrial fibrillation and CAA, resulting in clinical management dilemmas. Patients with CAA and atrial fibrillation have an indication for anticoagulation to reduce ischemic stroke risk and an elevated risk of intracranial hemorrhage. An individualized approach with a multidisciplinary team is recommended in these patients, taking into account the patient's preference, the patient's risk of ischemic stroke ( $\mathrm{CHA}_{2} \mathrm{DS}_{2}$ Vasc), the burden of CAA detected on MRI, and medical comorbidities. No prospective trials of treatment approaches in this patient population have been conducted, but warfarin should generally be avoided in favor of DOACs or left atrial appendage closure if the ischemic stroke risk justifies treatment. $^{77}$ 


\section{Oral anticoagulation}

Why and when should we treat with warfarin, and should DOACs be first line?

Oral anticoagulation options in the care of atrial fibrillation patients have expanded in the past 10 years beyond the well established VKAs, such as warfarin, which are limited by drug-drug and drug-food interactions, the need for frequent blood tests/INR testing, and notoriously variable time in therapeutic range. ${ }^{78-80}$ The availability of the DOACs in clinical practice (dabigatran, rivaroxaban, apixaban, and edoxaban) has dramatically changed the landscape of anticoagulation. They are increasingly preferred over VKAs in eligible patients owing to their ease of use, avoidance of frequent blood draws for therapeutic monitoring, lower risk of intracranial bleeding, and decreased concerns about drug and food interactions. Also, DOACs have a rapid onset of action and short half-life and attain more predictable blood concentrations, allowing standard fixed dosing regimens and obviating the need for laboratory monitoring (table 1). These factors, along with lower risk of major bleeding including intracranial hemorrhage, provide considerable advantages of DOACs over warfarin for thromboembolic prophylaxis in patients with atrial fibrillation. . $^{61-83}$

Since the introduction of DOACs, an increase has been reported in the use of guideline recommended therapy in patients newly diagnosed as having atrial fibrillation and at risk of stroke. ${ }^{84}$ In patients with acute ischemic stroke and atrial fibrillation, DOAC use at discharge was associated with better long term outcomes relative to warfarin. ${ }^{86}$ In the seminal randomized trials, DOACs have been shown to be as effective as or more effective than warfarin in preventing stroke irrespective of the patients' comorbidities, as they conferred similar or lower rates of both ischemic stroke and major bleeding, as shown in several randomized trials. ${ }^{87-92}$ In a meta-analysis of 13 RCTs in patients with venous thromboembolism or atrial fibrillation, DOACs were associated with a significantly lower risk of major bleeding (relative risk $0.72,95 \%$ confidence interval 0.62 to 0.85 ;
$\mathrm{P}<0.01 ; \mathrm{I}^{2}=78 \%$ ), fatal bleeding $(0.53,0.43$ to 0.64 ; $\left.\mathrm{P}<0.01 ; \mathrm{I}^{2}=0 \%\right)$, intracranial hemorrhage $(0.43$, 0.37 to $\left.0.50 ; \mathrm{P}<0.01 ; \mathrm{I}^{2}=2 \%\right)$, clinically relevant non-major bleeding (0.78, 0.68 to $0.90 ; \mathrm{P}<0.01$; $\left.\mathrm{I}^{2}=89 \%\right)$, and total bleeding $(0.76,0.71$ to 0.82 ; $\left.\mathrm{P}<0.01 ; \mathrm{I}^{2}=86 \%\right)$. No significant difference was seen in major gastrointestinal bleeding between DOACs and VKAs (relative risk $0.94,0.75$ to $1.99 ; \mathrm{P}=0.62$, $\left.\mathrm{I}^{2}=71 \%\right) .{ }^{93}$ Another meta-analysis that included data from four RCTs in patients with atrial fibrillation concluded that DOACs have a favorable risk-benefit profile compared with warfarin, with significant reductions in stroke (relative risk $0.81,0.73$ to 0.91 ; $\mathrm{P}<0.001)$, intracranial hemorrhage $(0.48,0.39$ to 0.59 ; $\mathrm{P}<0.0001)$, and mortality $(0.90,0.85$ to 0.95 ; $\mathrm{P}<0.001)$. The risk of major bleeding was similar to that with warfarin, but the risk of gastrointestinal bleeding was greater with DOACs (relative risk 1.25, 1.01 to $1.55 ; \mathrm{P}=0.04) .^{94}$ Other studies have also shown a reduction in fatal bleeding with DOACs compared with VKAs. ${ }^{95-97}$

Although DOACs have a safer bleeding profile than warfarin, major bleeding still occurs in about 3-4\% of patients taking DOACs every year. ${ }^{98}$ Despite a lower incidence than warfarin, intracranial hemorrhage associated with DOAC usage remains a concern. Intracranial hemorrhage is responsible for up to $45 \%$ of all bleeding related deaths in DOAC treated patients and carries a fourfold increased risk of mortality compared with major extracranial bleeds. ${ }^{99}$ One of the key concerns with the initial DOAC experience was the lack of reversal agents. The recent availability of reversal agents for DOACs is anticipated to further increase the comfort level of clinicians and patients using these agents. ${ }^{100101}$ However, feedback from our patient reviewers suggests that the greater familiarity and experience with warfarin reversal remains a major advantage of warfarin over DOACs from their perspective. Clinicians should also be aware that DOACs remain expensive and may not be affordable for many patients across different healthcare systems and medication reimbursement programs.

Finally, DOACs are contraindicated in patients with mechanical valve prostheses owing to an increased

\begin{tabular}{|c|c|c|c|c|c|}
\hline Characteristic & Dabigatran & Rivaroxaban & Apixaban & Edoxaban & Warfarin \\
\hline $\begin{array}{l}\text { Mechanism of } \\
\text { action }\end{array}$ & $\begin{array}{l}\text { Direct thrombin } \\
\text { inhibitor }\end{array}$ & $\begin{array}{l}\text { Factor Xa } \\
\text { inhibition }\end{array}$ & $\begin{array}{l}\text { Factor Xa } \\
\text { inhibition }\end{array}$ & $\begin{array}{l}\text { Factor Xa } \\
\text { inhibition }\end{array}$ & $\begin{array}{l}\text { Prevents availability of } \\
\text { vitamin } K \text { dependent } \\
\text { clotting factors }\end{array}$ \\
\hline Dosing for NVAF & $150 \mathrm{mg}$ twice daily & $25 \mathrm{mg}$ once daily & $5 \mathrm{mg}$ twice daily & $60 \mathrm{mg}$ once daily & Adjusted according to INR \\
\hline Time to peak & 1.5 hours & $2-4$ hours & $3-4$ hours & $1-2$ hours & $\begin{array}{l}\text { Variable (days) depending } \\
\text { on vitamin K concentrations }\end{array}$ \\
\hline Half life & $9-16$ hours & 6-9 hours & 9-14 hours & 10-14 hours & 40 hours \\
\hline Excretion & $80 \%$ renal & $\begin{array}{l}67 \% \text { renal (half of it as } \\
\text { inactive form) }\end{array}$ & $\begin{array}{l}25 \% \text { renal and } 75 \% \\
\text { fecal }\end{array}$ & $\begin{array}{l}50 \% \text { renal (unchanged); } \\
\text { also bile, feces }\end{array}$ & $\begin{array}{l}\text { Liver, primarily by } \\
\text { CYP2C9 }\end{array}$ \\
\hline Reversal strategy & $\begin{array}{l}\text { Idarucizumab (specific); } \\
\text { PCC and recombinant factor } \\
\text { VIlla (non-specific) }\end{array}$ & $\begin{array}{l}\text { Andexanet (specific); } \\
\text { PCC and recombinant factor } \\
\text { VIlla (non-specific) }\end{array}$ & $\begin{array}{l}\text { Andexanet (specific); } \\
\text { PCC and recombinant } \\
\text { factor VIIa (non-specific) }\end{array}$ & $\begin{array}{l}\text { Andexanet (specific); PCC } \\
\text { and recombinant factor VIIa } \\
\text { (non-specific) }\end{array}$ & $\begin{array}{l}\text { Fresh frozen plasma; } \\
\text { administration of } \\
\text { vitamin K }\end{array}$ \\
\hline $\begin{array}{l}\text { Special } \\
\text { considerations }\end{array}$ & $\begin{array}{l}\text { Avoid if } \mathrm{CrCl}<30 \mathrm{~mL} / \mathrm{min} \text { or } \\
\text { Child-Pugh class } \mathrm{B} \text { and } \mathrm{C} \text {, if } \\
\text { dyspepsia or upper } \\
\text { gastrointestinal symptoms }\end{array}$ & $\begin{array}{l}\text { Avoid if } \mathrm{CrCl}<30 \mathrm{~mL} / \mathrm{min} \text { or } \\
\text { Child-Pugh class B and C; } \\
\text { take with food }\end{array}$ & $\begin{array}{l}\text { Avoid if } \mathrm{CrCl}<15 \mathrm{~mL} / \\
\text { min or Child-Pugh class } \\
\mathrm{B} \text { and } \mathrm{C}\end{array}$ & $\begin{array}{l}\mathrm{CrCl} 15-30 \mathrm{~mL} / \mathrm{min} \text { use } \\
30 \mathrm{mg} \text { daily; avoid if } \mathrm{CrCl} \\
<15 \mathrm{~mL} / \mathrm{min}\end{array}$ & $\begin{array}{l}\text { Careful monitoring } \\
\text { warranted in severe liver } \\
\text { and kidney disease }\end{array}$ \\
\hline
\end{tabular}

$\mathrm{CrCl}=\mathrm{creatinine}$ clearance; INR=international normalized ratio; $\mathrm{NVAF}=$ non-valvular atrial fibrillation; $\mathrm{PCC}=$ prothrombin complex concentrates. 
risk of thrombosis. ${ }^{102}$ Even though very few patients with severe native valve disease and bioprosthetic valve prostheses were included in the DOAC trials, subsequent analyses have shown that DOACs are reasonable choices in these patients, except for those with severe rheumatic mitral stenosis. ${ }^{103}$ Although the initial trials of these agents excluded patients with end stage renal disease on dialysis, the use of apixaban in clinical practice has shown reasonable safety and effectiveness in this patient population ${ }^{104}$; however, this is not the case for dabigatran and rivaroxaban. ${ }^{105}$ Emerging data also suggest that the DOACs are safe and effective in patients with atrial fibrillation and hypertrophic cardiomyopathy. ${ }^{106}$

Reasons to withhold or stop anticoagulation

Generally, most patients with atrial fibrillation should be treated with anticoagulation. Making the distinction between relative and absolute contraindications for anticoagulation can be challenging and controversial. ${ }^{107-111}$ Absolute contraindications to the use of anticoagulation therapy may include severe thrombocytopenia, recent trauma or surgery, recent hemorrhagic stroke, recent intracranial hemorrhage, intracranial masses, or decompensated liver disease. ${ }^{10} 112113$ Clinicians need to carefully assess each of these risks and weigh the risk of a life threatening bleed against the risk of disabling stroke when withholding anticoagulation.

Although not without controversy, percutaneous left atrial appendage occlusion with a Watchman device (Boston Scientific, St Paul, MN) is an alternate non-pharmacologic method of reducing embolic strokes in atrial fibrillation patients at high risk and with contraindications to long term anticoagulation. ${ }^{114115}$ The premise of this approach is that most $(>90 \%)$ thrombi related to atrial fibrillation are formed in the left atrial appendage. The landmark PROTECT-AF trial showed that left atrial appendage occlusion was non-inferior to warfarin for preventing the combined outcome of stroke, systemic embolism, and cardiovascular death (hazard ratio $0.40,95 \%$ confidence interval 0.21 to $0.75 ; \mathrm{P}=0.005)$ and all cause mortality $(0.66,0.45$ to $0.98 ; \mathrm{P}=0.04) .{ }^{116}$ Subsequent randomized clinical trials, including the PREVAIL and the ASAP studies, as well as patient level meta-analyses reaffirmed the non-inferiority of left atrial appendage occlusion over warfarin in various clinical scenarios and regimens, ${ }^{117-119}$ but much of the benefit seems to be related to averted intracranial bleeds, rather the prevention of cardioembolic stroke.

Ongoing studies will evaluate the device in patients with absolute contraindications to anticoagulation or in comparison with the DOACs, which may have a more favorable bleeding profile in some patients. In addition to the now well established Watchman device, many other left atrial appendage occlusion devices are being evaluated in clinical trials and are expected to receive approval for routine clinical use soon. Surgical and minimally invasive thoracoscopic options for the exclusion of the left atrial appendage are also available.

\section{Underuse of anticoagulants}

The underuse of anticoagulation is an ongoing problem. In one study, fewer than half of eligible patients with a new diagnosis of atrial fibrillation were started on oral anticogulants. ${ }^{120}$ Underuse of oral anticoagulation has also been shown to be highly prevalent among atrial fibrillation patients admitted with a stroke. ${ }^{121}$ Despite the availability of convenient options for oral anticoagulation with the DOACs, its use has increased only modestly in recent years. ${ }^{122}$ Importantly, discontinuation of anticoagulation seems to be most common in patients at high risk of stroke, including older adults and women.

The reasons for such underuse of oral anticoagulation likely include healthcare, provider, and patient related factors. For example, the perceived balance of stroke versus bleeding risk and the priorities in care may be different from the perspective of the primary care provider who focuses on a simplified care model that minimizes polypharmacy compared with the neurologist who cares for patients with debilitating strokes. Patients' perspectives on oral anticoagulation, knowledge gaps, and even financial constraints likely also affect the rates of use. Educational interventions alone may not always translate to improvement of clinical outcomes. These interventions are most likely to be successful when they involve all pertinent stakeholders, including the patient's primary and specialty care clinicians and, most critically, the patients themselves. ${ }^{123124}$

\section{Role of rhythm control}

For the patient presenting to the primary care clinic with a new diagnosis of atrial fibrillation, the first decision point hinges on whether to pursue a rhythm control or a rate control strategy (fig 3). Patients with ongoing atrial fibrillation at the time of initial evaluation, as confirmed by 12 lead electrocardiography, and with very slow or rapid ventricular rates (typically $<40 \mathrm{bpm}$ and $>150 \mathrm{bpm}$ ), evidence of hemodynamic instability, severe symptoms, or decompensated heart failure should be referred to the emergency department for stabilization and possible electrical cardioversion. In case of unknown duration of atrial fibrillation, cardioversion should be preceded by transesophageal echocardiography to rule out intracardiac thrombus. Patients are required to be on anticoagulation for at least four weeks after electrical cardioversion to reduce the risk of thromboembolism.

Although the choice between rate and rhythm control has generally been considered not to have an effect on hard clinical outcomes, such as survival, ${ }^{125} 126$ rhythm control should be favored in the presence of significant atrial fibrillation related symptoms or presumed tachycardia induced cardiomyopathy. ${ }^{127}$ A rhythm control approach may also be preferable in younger ( $<65$ years) patients with paroxysmal atrial fibrillation, as rate control alone is likely to result in progression to longstanding 


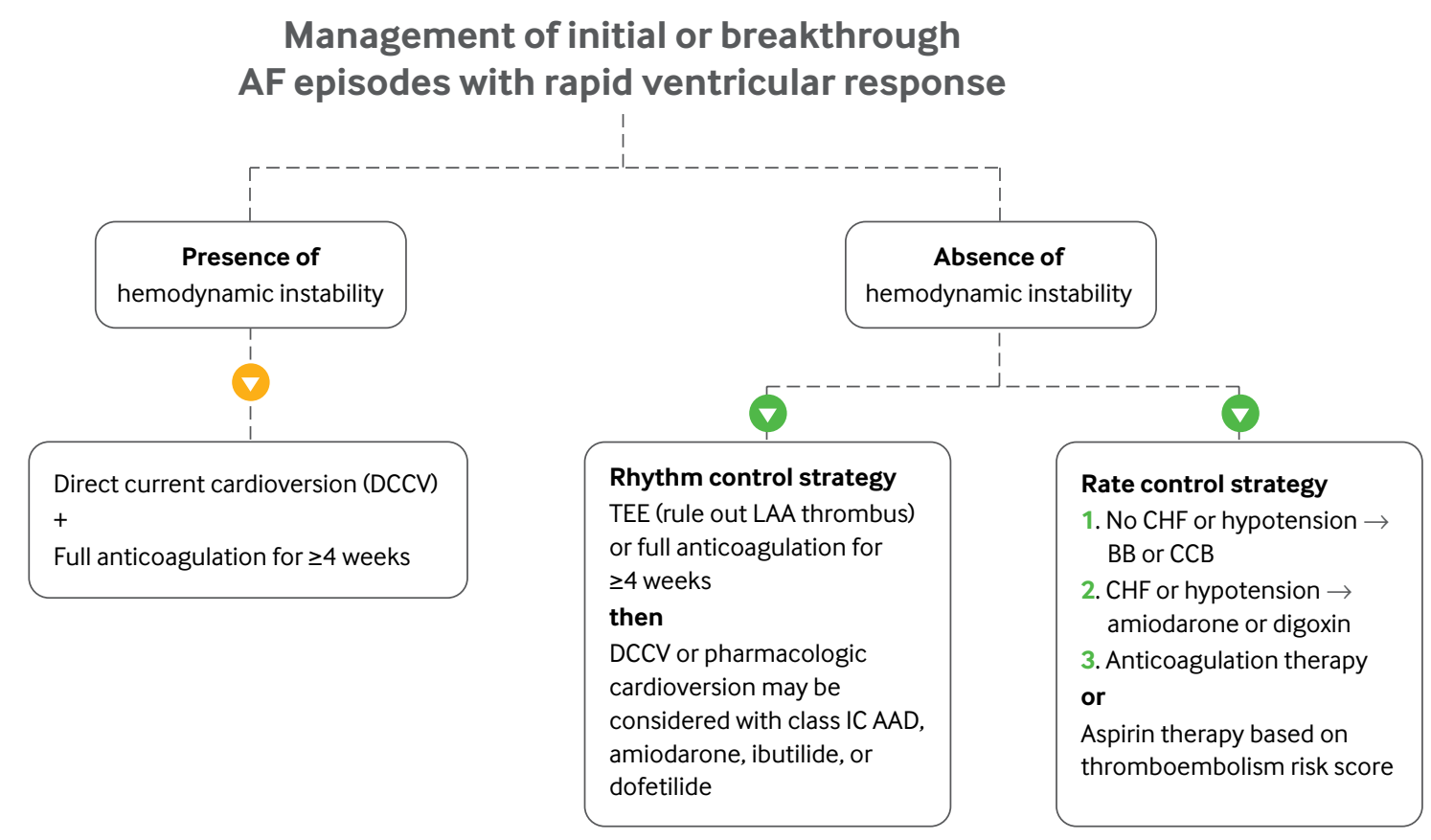

Fig 3 | Algorithm for management of initial and breakthrough atrial fibrillation (AF) episodes. $A A D=$ antiarrhythmic drug; $B B=\beta$ blocker; $C C A=c a l c i u m$ channel antagonist; $C H F=$ congestive heart failure; $L A A=l$ eft atrial appendage; $T E E=$ transesophageal echocardiography

persistent atrial fibrillation over a period of time, which will later be more difficult to control and carries a risk of development of tachycardia induced cardiomyopathy. ${ }^{128}$ Young patients may be particularly prone to side effects from rate controlling agents, including fatigue, erectile dysfunction, or depression. ${ }^{129} 130$

If an early rhythm control strategy is chosen, an elective electrical or pharmacologic cardioversion may be performed shortly after diagnosis of atrial fibrillation. We acknowledge, however, that in some cases-for instance, if atrial fibrillation is incidentally detected in a patient with severe comorbidities-an initial rate control strategy may be reasonable. For subsequent episodes, the decision to pursue rate or rhythm control depends on the factors discussed above. The recently completed EAST-AFNET 4 trial provides contemporary evidence in support of an early rhythm control approach. ${ }^{131}$ It randomized nearly 2800 patients to rhythm or rate control early after their initial diagnosis of atrial fibrillation (median time from diagnosis 36 days). Patients in the rhythm control group had a significantly lower incidence of a composite clinical endpoint, including cardiovascular death, stroke, or hospital admission for heart failure or acute coronary syndrome, compared with the rate control group $(3.9 v 5.0$ per 100 person years; hazard ratio $0.79,95 \%$ confidence interval 0.66 to $0.94 ; \mathrm{P}=0.005$ ).

Rhythm control: antiarrhythmic drugs

Several antiarrhythmic drugs have been widely used for the past several decades as first line or second line approaches and often adjunctively with an ablation approach. Flecainide and propafenone (class Ic antiarrhythmics ${ }^{132}$ ) are typically used in paroxysmal atrial fibrillation and can be used as a pill-in-pocket approach or as scheduled medications. These can typically be initiated in an outpatient setting. Class Ic drugs can have a proarrhythmic effect in the presence of structural heart disease, ${ }^{133}$ mainly myocardial scar, so their use is reserved for patients with structurally normal hearts. Class III antiarrhythmics such as sotalol and dofetilide can be used in both paroxysmal and persistent atrial fibrillation. ${ }^{134} 135$ Their antiarrhythmic action is related to their effect on prolongation of myocardial repolarization. They have an expected effect on prolongation of the QTC interval, but when this effect is exaggerated they can provoke potentially fatal ventricular arrhythmias (such as torsades de pointes). Therefore, initiation of these drugs warrants admission to hospital for continuous rhythm monitoring and serial electrocardiograms for QTc interval monitoring for the first five or six doses. This practice may vary between different healthcare systems.

Amiodarone is the most effective antiarrhythmic, ${ }^{136}$ but owing to its toxicity profile it is reserved as a last resort option in patients who have not responded to or not tolerated other antiarrhythmic drugs or catheter ablation. ${ }^{137}$ The risk of cardiac, pulmonary, thyroid, liver, and ocular toxicities, among other toxicities, is time and dose dependent. Therefore, amiodarone should be avoided in younger patients. When necessary, it is prescribed at the lowest necessary dose, for the shortest time possible, and under close monitoring as discussed later in this review. Dronedarone is structurally and mechanistically similar to amiodarone but lacks the side effect profile of amiodarone. However, its lower 
effectiveness and other safety concerns have made it a less popular option in the current armamentarium for atrial fibrillation.

The choice of a specific anti-arrhythmic drug is tailored to the individual patient on the basis of their atrial fibrillation phenotype, goals of therapy, and cardiac and non-cardiac comorbidities. Given the complexities described above, shared decision making and guidance on the prescription of antiarrhythmic drugs should involve specialists and primary care physicians.

Rhythm control: role of catheter based interventions The discovery of ectopic beats from the pulmonary veins triggering paroxysmal atrial fibrillation in humans led to the development of catheter based pulmonary vein isolation as an interventional strategy for the treatment of atrial fibrillation..$^{138} 139$ The 2014 AHA/ACC/HRS guideline for the treatment of atrial fibrillation places ablation as a class I option for the treatment of symptomatic drug refractory persistent atrial fibrillation, but ablation of paroxysmal atrial fibrillation before drug failure is a class IIa recommendation. ${ }^{64}$ The procedure is directed toward electrically isolating the atrial fibrillation triggers in the pulmonary veins along with supplementary modification of the atrial fibrillation substrate to prevent recurrence of atrial fibrillation and improve the outcomes of the procedure. ${ }^{140}$

Many studies have evaluated adjuvant ablation strategies to improve rhythm control outcomes in persistent atrial fibrillation, but results are mixed with some studies showing no additional benefit and other showing only marginal gains. ${ }^{141} 142$ Ablation can be performed with thermal tissue injury with radiofrequency energy or tissue freezing with a cryoballoon, ${ }^{143-145}$ with similar success rates and safety profile. ${ }^{146-149}$ Novel approaches including renal denervation through ablation of the renal sympathetic efferent and afferent nerves have been evaluated as a treatment for resistant hypertension and improving the success of atrial fibrillation ablation. ${ }^{150-152}$

Catheter ablation is effective in reducing the burden of both paroxysmal and persistent atrial fibrillation In the largest catheter ablation trial to date, the CABANA trial, which randomized 2204 patients with atrial fibrillation to catheter ablation or drug therapy, catheter ablation reduced recurrences of atrial fibrillation by $48 \%$ compared with antiarrhythmic drug therapy over five years of follow-up. In the trial, the patients in the catheter ablation group experienced significant reduction in both first recurrence of any symptomatic or asymptomatic atrial fibrillation (hazard ratio 0.52 , 0.45 to $0.60 ; \mathrm{P}<0.001)$ or first symptomatic-only atrial fibrillation $(0.49,0.39$ to $0.61 ; \mathrm{P}<0.001)$ at five years of follow-up. ${ }^{153}$ In the recent CIRCA-DOSE trial-in which 346 patients with drug refractory paroxysmal atrial fibrillation were randomized to contact force guided radiofrequency ablation $(n=115)$, four minute cryoballoon ablation $(n=115)$, or two minute cryoballoon ablation ( $n=116)-$ catheter ablation with radiofrequency or cryoballoon resulted in freedom from atrial tachyarrhythmias in slightly more than half of patients, without a difference between ablation approaches (53.9\%, $52.2 \%$, and $51.7 \%$ with force guided radiofrequency ablation, four minute cryoballoon ablation, and two minute cryoballoon ablation, respectively; $\mathrm{P}=0.87) .{ }^{154}$ That reduced atrial fibrillation burden may translate to a lower risk of stroke and other hard outcomes for patients may seem intuitive, but the CABANA and other atrial fibrillation ablation trials have shown no clear reductions in endpoints such as stroke, death, cardiac arrest, or major bleeding with ablation compared with medical therapy. ${ }^{155} 156$ However, the role for early rhythm control remains controversial. In contrast to CABANA, the EAST trial, discussed earlier in this review, showed a reduction in a composite of cardiovascular death, stroke, or hospital admission for heart failure or acute coronary syndrome with early rhythm control. ${ }^{131}$ However, less than $10 \%$ of patients in this study underwent ablation as the initial rhythm control strategy. Although dedicated ablation trials such as RAAFT-1, RAAFT-2, and MANTRA-PAF have not, to date, shown such benefits with ablation alone, ${ }^{157-159}$ they showed significant improvement in quality of life and reduction in recurrence of symptomatic atrial fibrillation and associated hospital admissions, suggesting its feasibility as a first line approach for treating patients with symptomatic atrial fibrillation.

\section{Integrated, primary care centered model of care}

Like many other chronic diseases, atrial fibrillation can be managed effectively in the primary care setting, often through engagement with specialty and support services. Among the most established models for integrated care are the thrombosis or anticoagulation clinics that are responsible for INR monitoring and dose adjustment of warfarin anticoagulation under the direction of or in collaboration with primary care. Although the role for these clinics may be diminished with the widespread adoption of DOACs, in some instances they remain a resource for collaborative atrial fibrillation care regarding medication safety more generally. ${ }^{160}$

Beyond anticoagulation, engagement of specialty cardiology or electrophysiology is often necessary. Common reasons for referral include failure of an initial rate control approach, frequent paroxysms of symptomatic atrial fibrillation, persistently elevated heart rate, or intolerance of rate controlling drugs. A first line rhythm control approach may be considered necessary in some patients, and these patients should be evaluated in specialty cardiology or electrophysiology clinics. Rhythm control, particularly with an ablation based approach, has shown consistent benefits in patients with pre-existing heart failure or presumed tachycardia induced cardiomyopathy at the time of presentation with atrial fibrillation. ${ }^{155} 161$ In addition, antiarrhythmic drugs may often be started 
under specialty care given the need for monitoring at initiation, presence of many drug-drug interactions, and risk of serious cardiac and non-cardiac toxicities. The timing of referral may be determined on a case by case basis, but some data suggest that early referral for consideration of rhythm control may be associated with improved long term control of atrial fibrillation. ${ }^{162}$ Patients presenting with atrial fibrillation and thromboembolism or other high risk features, such as syncope, angina, or slow ventricular rate may also benefit from early specialty consultation and advanced therapies. Clinicians may consider specialty referral for the conditions and scenarios listed in box 1 .

Although several subspecialists are involved in the care of most atrial fibrillation patients, the primary care setting is central in the longitudinal monitoring and follow-up. With easier access compared with subspecialty clinics, people with atrial fibrillation have a more direct path to primary care to report breakthrough symptoms and revise the treatment plan when necessary. To maximize convenience for patients, routine follow-up for atrial fibrillation may not always necessitate in-person visits. Both atrial fibrillation symptoms and rhythm can be monitored virtually with online patient questionnaires, smartwatch enabled rhythm monitoring, and ambulatory patch rhythm monitoring. The primary care clinician may also be the first contact for a patient experiencing an atrial fibrillation related complication, such as a neurologic event or heart failure decompensation.

An integrated system that facilitates quick interaction between patients, primary care clinicians, and specialized clinics can efficiently adjust the treatment plan to meet the patient's needs and streamline care (fig 4). In such a system, the primary care clinician can be compared to the quarterback coordinating a team including the cardiologist or electrophysiologist, the neurologist, the anticoagulation expert, and the sleep specialist, among others. Central to such a system are also trained nurses who can directly

Box 1: Indications for referral to specialty care

- Initial rate control approach has failed or is not well tolerated

- First line rhythm control approach is being considered

- Pre-existing or newly diagnosed concomitant structural heart disease, such as moderate or severe valvular dysfunction, amyloidosis, hypertrophic cardiomyopathy, or congenital heart defect.

- Suspicion of significant coronary artery disease based on clinical history or objective testing

- Recent syncope

- Atrial fibrillation with slow ventricular rate $(<40 \mathrm{bpm})$ or conversion pauses from atrial fibrillation to sinus rhythm exceeding $3 \mathrm{~s}$ or with associated symptoms

- Stroke, transient ischemic attack, or peripheral embolism at the time of initial presentation

- Young patients ( 655 years of age) with new atrial fibrillation

- Complex anticoagulation decision making in atrial fibrillation patients at high risk of bleeding, such as those with cerebral amyloid angiopathy-consider left atrial appendage closure

- Patient or clinician preference liaise with the patient, provide education, and help them to interact with specialists and navigate the care system in a way that is minimally disruptive for the patient. In addition to promoting satisfaction among patients and clinicians, such models may reduce cardiovascular and all cause mortality. ${ }^{163} 164$ The 2016 European Society of Cardiology guidelines adopted and promoted a structured multidisciplinary approach to care as the recommended approach to management of atrial fibrillation. ${ }^{165}$

Monitoring and follow-up of atrial fibrillation should include ongoing assessment of the progress with lifestyle recommendations. Feedback from our atrial fibrillation patient reviewers suggests that treating clinicians sometimes place little emphasis on lifestyle counseling. The role of risk factor control, such as weight loss, cardiometabolic fitness, blood pressure reduction, and obstructive sleep apnea management has been well established in the past decade. Abstinence from alcohol was recently shown to reduce atrial fibrillation episodes among regular drinkers with atrial fibrillation in a randomized trial. ${ }^{166}$ Patients actively engaged in comprehensive risk factor management programs have fewer atrial fibrillation related symptoms, higher quality of life scores, and improved rhythm control after catheter ablation. $^{36} 37$ The unpredictable sustainability of these lifestyle interventions can challenge their long term effectiveness. Longitudinal engagement and reinforcement of their value is therefore important in the primary care setting.

For patients taking antiarrhythmic drugs, routine monitoring for adherence, efficacy, and toxicities is important. For sotalol and dofetilide, patients should undergo evaluation of the QTc interval and renal function every six months. ${ }^{64167}$ For patients on long term amiodarone, any opportunity should be taken for clinical screening for symptoms or signs of hepatic, thyroid, pulmonary, skin, and eye toxicities. Guidance on laboratory monitoring varies across practices, but hepatic and thyroid function should be assessed six months after drug initiation and every six to 12 months thereafter. Pulmonary function should be assessed annually. Patients should be referred for eye examination annually. Patients should also undergo electrocardiography at least annually to assess for sinoatrial or conduction system dysfunction related to amiodarone. Amiodarone also prolongs the QTc interval in most patients, but unlike other QT interval prolonging drugs, this effect is very rarely torsadogenic. ${ }^{64168}$

Ongoing research continues to highlight the importance of a multifaceted approach that considers all of the above aspects in patients with atrial fibrillation. For example, in the recently proposed ABC pathway, the "A" criterion is fulfilled if the patient has a time in the therapeutic anticoagulation range of $70 \%$ or higher, the " $\mathrm{B}$ " criterion is fulfilled if the patient has two or fewer atrial fibrillation related symptoms, and the "C" criterion is fulfilled if the patient is properly managed for the concomitant comorbidities. Atrial fibrillation care in accordance 


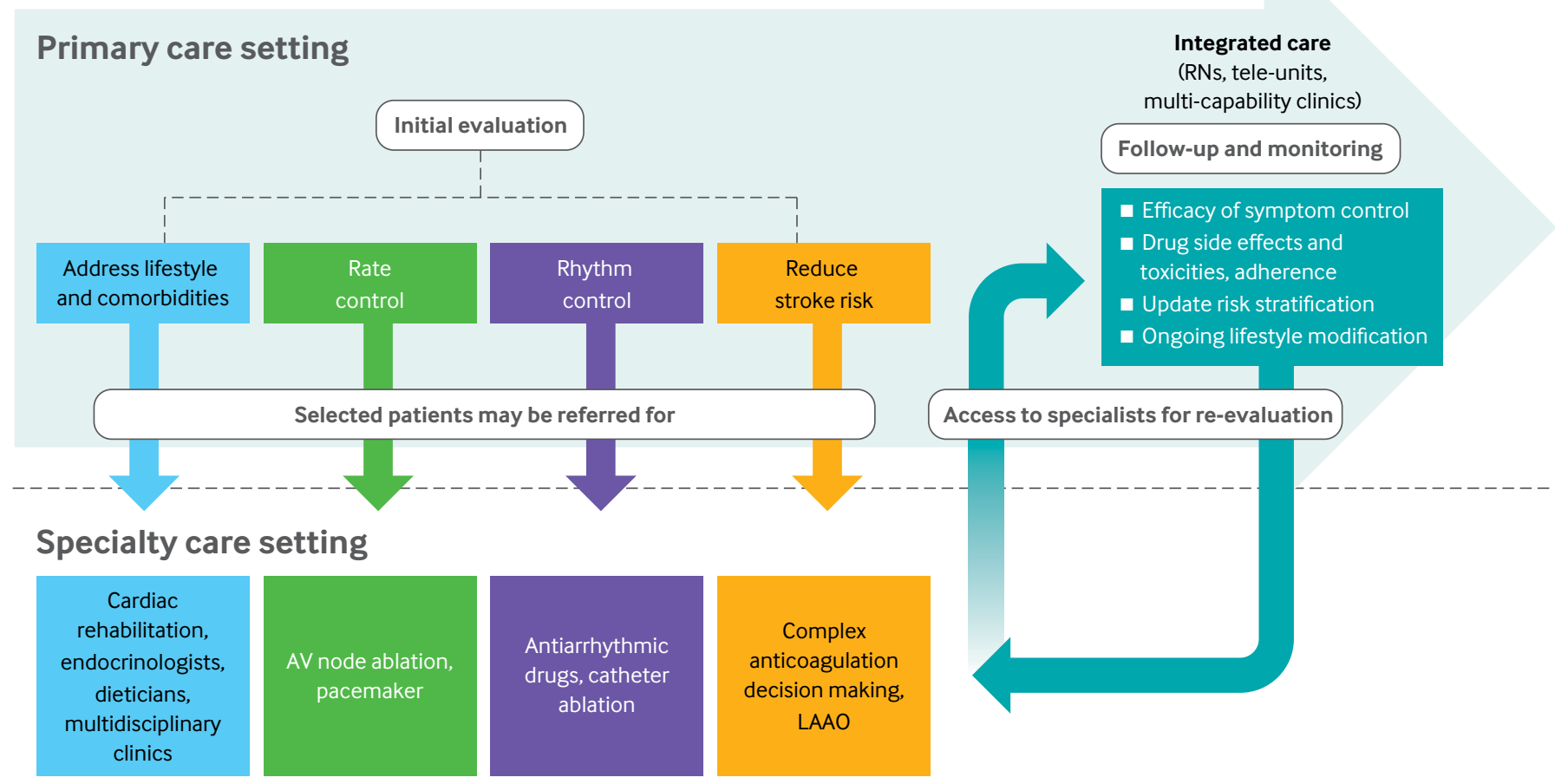

Fig 4 | Model for integration of primary and specialty/multidisciplinary care for atrial fibrillation. AV=atrioventricular; LAAO=left atrial appendage occlusion; $\mathrm{RN}=$ registered nurse

with this pathway was recently shown to be associated with 30-40\% lower risk of the composite outcome of all cause hospital admission and death in a complex atrial fibrillation population. ${ }^{169}$ The same ABC pathway was also recently evaluated in a randomized trial comparing integrated care based on a mobile atrial fibrillation application with usual care in patients with atrial fibrillation. ${ }^{170}$ The rates of ischemic stroke/systemic thromboembolism, death, and readmission to hospital were lower with the $\mathrm{ABC}$ intervention compared with usual care $(1.9 \%$ $v$ 6.0\%; hazard ratio $0.39,0.22$ to $0.67 ; \mathrm{P}<0.001$ ). Mobile technologies may facilitate multifaceted care for complex patients.

\section{Shared decision making with patients}

Patient centered care should promote shared decision making in difficult clinical scenarios. ${ }^{171}$ Patient centered care can be defined as "care that is respectful of and responsive to individual patient needs, values, and preferences" and that ensures "the patient's values guide all clinical decisions." 172173 Discussions about anticoagulation, especially in older patients with increased risk of bleeding, can be complicated and time consuming.

The goals of atrial fibrillation care need to be established early in the disease course between patient and clinician. The key priority is the prevention of thromboembolism, and clinicians should ensure that patients are well informed and aware of the rationale for anticoagulation. A recent European survey of patients with atrial fibrillation showed that one in 10 patients thought that their anticoagulant would treat the arrhythmia rather than lower their risk of stroke. ${ }^{174}$ In another survey in the US, almost two thirds of atrial fibrillation patients were not aware that atrial fibrillation is associated with an increased risk of stroke. ${ }^{175}$ The frequent interactions and established relationship of trust between a patient and his or her primary care provider make primary care the ideal setting for such misconceptions to be tackled. In terms of arrhythmia control, this becomes a priority in patients with highly symptomatic atrial fibrillation and in those with heart failure related to their atrial fibrillation. Despite major advances in the treatment of atrial fibrillation, it has no cure. The goals of antiarrhythmic drugs and ablation procedures are to reduce symptoms and recurrences of atrial fibrillation rather than to cure atrial fibrillation; most patients will have recurrent arrhythmia even after any antiarrhythmic intervention. Realization of these limitations of current treatment modalities can help patients to better align their own goals and expectations and promote a lasting therapeutic interaction with their clinician.

\section{Guidelines}

Table 2 summarizes the major guideline recommendations from the American societies (AHA/ACC/HRS) as well as the European societies (the European Society of Cardiology, the European Association for Cardiothoracic Surgery, and the European Heart Rhythm Society). ${ }^{64} 176$ The table includes a summary of the recommendations on screening for atrial fibrillation, the threshold for starting of oral 


\section{Table 2 | Comparison of guideline recommendations from 2014 American Heart Association/American College of Cardiology/Heart Rhythm Society (AHA/ACC/HRS) and European Society of Cardiology/European Association for Cardiothoracic Surgery (ESC/EACTS) for management of atrial fibrillation (AF) \\ Parameter \\ AHA/ACC/HRS \\ COR (LOE) \\ COR (LOE)}

Screening for silent AF and device detected atrial high rate episodes
A "smart" worn or handheld wifi enabled device with $\| \mathrm{Ia}(\mathrm{B}-\mathrm{R})$

remote interpretation can be used for AF screening

Screening in patients with cryptogenic stroke and

inconclusive external ambulatory monitoring, implantation

of a cardiac monitor (loop recorder) is reasonable

AHREs detected on CIEDs should prompt furthe

evaluation to identify clinically relevant AF

Threshold duration of AHREs that warrants OAC is unclear and decision to start OAC may be guided by individual patient's stroke risk profile, bleeding risk. and preferences

Threshold for starting OAC CHA2DS2-VASc score $\geq 2$ in men or $\geq 3$ in women: OAC I (A) is recommended

CHA2DS2-VASC score $\geq 1$ in men or $\geq 2$ in women: OAC IIb (C-LD) should be considered

\section{rhythm strip is recommended in patients $\geq 65$ years of age}

Ila (B-R) Systematic ECG screening should be considered to detect Ila (B)

$A F$ in individuals aged $\geq 75$ years or those at high risk of stroke

I (B-NR) CIEDs should be interrogated regularly for AHRES

IIb (C-EO) AF in screen positive cases is established only after

physician reviews single lead ECG recording of $\geq 30$ s or

12 lead ECG. Physician to provide optimal management of patients with confirmed $A F$

CHA2DS2-VASc score $\geq 2$ (male) or $\geq 3$ (female): OAC is I (A) recommended

CHA2DS2-VASc score 1 (male) or 2 (female): OAC should IIa (B) be considered

"Low stroke risk" patients with CHA2DS2-VASc score 0 (male) or 1 (female) should NOT be offered antithrombotic therapy

Choice of anticoagulant DOACs are recommended over warfarin in DOAC I (A) eligible patients* DOACs generally recommended as first line therapy for

Only warfarin recommended for NOAC ineligible $O A C$ in preference to VKAs in DOAC eligible patients patients†

DOACs are contraindicated in patients with prosthetic

mechanical valve and anticoagulation with VKAs is needed

In AF patients, no role for antiplatelet agents in stroke III (A) prophylaxis

Aspirin alone or in combination with clopidogrel is NOT recommended for stroke prophylaxis in $\mathrm{AF}$

Triple therapy with aspirin, clopidogrel, and an OAC

triple antithrombotic therapy) in patients with increased risk of strokeł >1 week only when risk of stent thrombosis outweighs bleeding risk, with total duration $\leq 1$ month

$$
\text { is preferred over prasugrel }
$$

Transition to double therapy (OAC and P2Y12

Ila (B-R)

After uncomplicated $\mathrm{PCI}$, early cessation ( $\leq 1$ week) of aspirin and continuation of dual therapy with OAC + clopidogrel for up to 6 months (in CCS) and 12 months (in ACS) is recommended

Double therapy with clopidogrel and low dose rivaroxaban $15 \mathrm{mg}$ daily OR dabigatran $150 \mathrm{mg}$ twice daily is reasonable to reduce risk of bleeding compared with triple therapy

Double therapy with clopidogrel or ticagrelor and dose adjusted VKA is reasonable to reduce risk of bleeding compared with triple therapy
Ila (B-R) In patients at high bleeding risk (HAS-BLED $\geq 3$ ), rivaroxaban $15 \mathrm{mg}$ once daily or dabigatran $110 \mathrm{mg}$ twice daily for duration of concomitant single or DAPT, to mitigate bleeding risk

Ila (B-R) In AF patients with indication for VKA in combination with antiplatelet therapy, VKA dosing should be carefully regulated with target INR of $2.0-2.5$ and TTR $>70 \%$

\begin{tabular}{|c|c|c|c|c|}
\hline \multicolumn{5}{|l|}{ Indications for catheter ablation: } \\
\hline \multirow{3}{*}{$\begin{array}{l}\text { Symptomatic and refractory } \\
\text { or intolerant to } \geq 1 \text { class I or III } \\
\text { antiarrhythmic drug }\end{array}$} & Recommended for paroxysmal AF & $\mathrm{I}(\mathrm{A})$ & Recommended for paroxysmal AF & I (A) \\
\hline & Reasonable for persistent AF & IIa (B-NR) & $\begin{array}{l}\text { Recommended for persistent AF without major risk } \\
\text { factors for AF recurrence }\end{array}$ & I (A) \\
\hline & May be reasonable for longstanding persistent AF & IIb (C-LD) & $\begin{array}{l}\text { Recommended for persistent AF with major risk } \\
\text { factors for AF recurrence }\end{array}$ & I (B) \\
\hline \multirow{3}{*}{$\begin{array}{l}\text { Symptomatic AF before } \\
\text { initiation of antiarrhythmic } \\
\text { therapy with class I or III } \\
\text { antiarrhythmic drug }\end{array}$} & Reasonable for paroxysmal AF & $\| \mathrm{la}(\mathrm{B}-\mathrm{R})$ & Reasonable for paroxysmal AF & Ila (B) \\
\hline & Reasonable for persistent AF & Ila (C-EO) & $\begin{array}{l}\text { Reasonable for persistent AF without major risk factors for } \\
\text { AF recurrence }\end{array}$ & Ila (C) \\
\hline & $\begin{array}{l}\text { May be considered for longstanding } \\
\text { persistent AF }\end{array}$ & IIb (C-EO) & $\begin{array}{l}\text { Reasonable for paroxysmal and persistent } A F \text { after failure } \\
\text { of or intolerance to } \beta \text { blocker treatment to improve } \\
\text { symptoms of } A F \text { recurrences }\end{array}$ & IIa (B) \\
\hline \multirow[t]{2}{*}{ Asymptomatic AF } & $\begin{array}{l}\text { May be considered in select patients with paroxysmal } \\
\text { AF }\end{array}$ & IIb (C-EO) & \multirow{2}{*}{$\begin{array}{l}\text { Recommended as first line therapy to reverse left } \\
\text { ventricular dysfunction with tachycardia induced } \\
\text { cardiomyopathy is highly probable, independent of their } \\
\text { symptom status }\end{array}$} & I (B) \\
\hline & $\begin{array}{l}\text { May be considered in select patients with persistent } \\
\text { AF }\end{array}$ & $\mathrm{IIb}(\mathrm{C}-\mathrm{EO})$ & & \\
\hline Heart failure & $\begin{array}{l}\text { May be reasonable in symptomatic AF and HFrEF to } \\
\text { potentially lower mortality rate and reduce hospital } \\
\text { admission for HF }\end{array}$ & IIb (B-R) & $\begin{array}{l}\text { Reasonable in selected AF patients with HF with reduced } \\
\text { LVEF to improve survival and reduce HF hospital } \\
\text { admissions }\end{array}$ & Ila (B) \\
\hline \multicolumn{5}{|l|}{ Indications for LAAC: } \\
\hline Percutaneous closure & $\begin{array}{l}\text { May be considered for stroke prevention in patients } \\
\text { with contraindications to long term OAC }\end{array}$ & IIb (B-NR) & $\begin{array}{l}\text { May be considered for stroke prevention in patients with } \\
A F \text { and contraindications for long term OAC }\end{array}$ & $\mathrm{IIb}(\mathrm{B})$ \\
\hline Surgical closure & Reasonable for AF patients undergoing cardiac surgery & IIb (B-NR) & Reasonable for AF patients undergoing cardiac surgery & $\mathrm{IIb}(\mathrm{C})$ \\
\hline \multicolumn{5}{|c|}{ 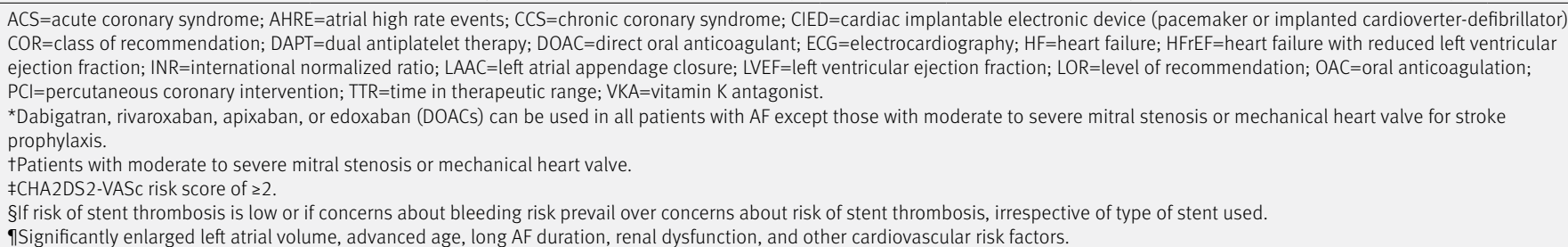 } \\
\hline
\end{tabular}

ISignificantly enlarged left atrial volume, advanced age, long AF duration, renal dysfunction, and other cardiovascular risk factors. 
anticoagulation, choice of anticoagulant, treatment after percutaneous coronary intervention (dual versus triple antithrombotic therapy), indications for catheter ablation for atrial fibrillation, and indications for left atrial appendage closure. General agreement exists between organizations for most recommendations. However, the European guidelines give slightly stronger recommendations than the US guideline for anticoagulation for intermediate risk patients (class Ia for patients with a CHA2DS2-VASc score of 1 (male) or 2 (female) versus a class Ib recommendation for CHA2DS2-VASc score $\geq 1$ in men or $\geq 2$ in women), for earlier de-escalation from triple to double therapy after percutaneous coronary intervention (class I recommendation for early cessation of aspirin and continuation of dual therapy following uncomplicated percutaneous coronary intervention versus a IIa recommendation for continued triple therapy for four to six weeks in the US guideline), and for catheter ablation in patients with persistent or longstanding persistent atrial fibrillation refractory to antiarrhythmic drugs (class I versus class IIa and IIb, respectively) or before antiarrhythmic drugs (class IIa versus IIb for longstanding persistent atrial fibrillation).

\section{Emerging treatments}

Although the landscape of antiarrhythmic drugs has not changed significantly in recent years, the field of catheter based ablation treatments for management of atrial fibrillation is rapidly evolving. The long term effectiveness of pulmonary vein isolation, the cornerstone of the ablative management of atrial fibrillation, is limited by the ability to generate transmural and durable atrial lesions. Achieving such lesions requires prolonged and high energy ablation that carries a risk of complications including pulmonary vein stenosis and damage to collateral structures (esophagus, phrenic nerve). A considerable amount of pre-clinical and early clinical data are being generated with the use of alternative catheter ablation energy types, such as pulsed field ablation (or electroporation). Pulsed field ablation has the potential advantage of tissue selectivity such that ablation energy results in desirable atrial myocardial injury, rather than collateral tissue damage. The first few published studies indicate favorable effectiveness and safety profile compared with conventional radiofrequency energy, ${ }^{177} 178$ but more data from larger and longer term multicenter studies are eagerly anticipated in the next one or two years. Eventually, ablation of atrial fibrillation may be achieved without an invasive catheter based approach, instead using technologies used in radiation oncology to deliver precise ablative radiation with stereotactic body radiation therapy. Early experience with ablation of ventricular arrhythmias has shown promise. ${ }^{179}$

\section{Conclusion}

The global burden of atrial fibrillation is rapidly increasing with our aging population and improved screening using wearable technology such as smartwatches. More studies may be needed to support the benefit of identifying and anticoagulating patients with atrial fibrillation detected through screening in preventing thromboembolic strokes. The availability of DOACs has significantly improved adherence to anticoagulation in patients with atrial fibrillation owing to their ease of use and improved safety. Although ablation of atrial fibrillation is recommended in patients with drug refractory symptoms, mounting data support increased

\section{RESEARCH QUESTIONS}

- How might clinicians screen targeted populations at risk for new or undetected atrial fibrillation in a way that is cost effective and minimally disruptive?

-What is the optimal stroke prevention strategy in patients at high risk for bleeding who cannot tolerate oral anticoagulation (for instance, patients with cerebral amyloid angiopathy)?

- Will novel and emerging ablation techniques improve the efficacy of atrial fibrillation catheter ablation for arrhythmia control and reduction of cardiovascular events?

-What is the best approach to the management of patients with atrial fibrillation detected incidentally by implanted cardiac devices (pacemakers or implantable cardioverter-defibrillators, for instance)?

- Can formal shared decision making processes improve atrial fibrillation care?

\section{PATIENT INVOLVEMENT}

We engaged a group of patient stakeholders (seven patients in total with one "lead" spokesperson) with atrial fibrillation to review and offer guidance on this manuscript. We identified these patients through the "Mayo Clinic Connect" platform, an online community in which patients can share their experiences and find support. An earlier draft of the manuscript was shared with the patient stakeholders for their review and feedback. Some of the main themes that emerged were:

- Striking data on common knowledge gaps, such as that atrial fibrillation is a risk factor for stroke and that anticoagulants do not treat the arrhythmia itself

- The critical role of primary care in coordinating the often complex problems that atrial fibrillation patients are faced with

- Implications of asymptomatic atrial fibrillation

- Perspectives on the importance of widespread availability of and longstanding experience with anticoagulant reversal as a key factor in preferring warfarin over direct acting oral anticoagulants (DOACs)

- Challenges with affordability of DOACs

- Limited emphasis placed on lifestyle counseling by primary care clinicians and cardiologists caring for atrial fibrillation patients 
success of the procedure with early intervention. With improved catheter designs and safety of existing atrial fibrillation ablation techniques, future studies may need to look at outcomes of early electrophysiological intervention in patients with asymptomatic screen detected atrial fibrillation as opposed to observation and rate control.

We thank the patient stakeholders (ML and MJ) and Mayo Clinic Connect for helping us to incorporate the patient's voice and perspective in the drafting and revision of this manuscript.

Contributors: SPP made substantial contributions to the design and initial drafting of the work (first complete draft), revising it critically for important intellectual content. KCS made substantial contributions to the conception or design of the work, revising it critically for important intellectual content. DRR, JGR, VM, and PAN made substantial contributions to the conception or design of the work, revising it critically for important intellectual content. All authors give final approval of the version to be published and are in agreement to be accountable for all aspects of the work in ensuring that questions related to the accuracy or integrity of any part of the work are appropriately investigated and resolved. PAN is the guarantor. Competing interests: We have read and understood the BMJ policy on declaration of interests and declare the following interests: None.

Provenance and peer review: Commissioned; externally peer reviewed.

1 Chugh SS, Havmoeller R, Narayanan K, et al. Worldwide epidemiology of atrial fibrillation: a Global Burden of Disease 2010 Study. Circulation 2014;129:837-47. doi:10.1161/ CIRCULATIONAHA 113.005119

2 Lippi G, Sanchis-Gomar F, Cervellin G. Global epidemiology of atrial fibrillation: An increasing epidemic and public health challenge. Int J Stroke 2021;16:217-21. doi:10.1177/1747493019897870

3 Frost L, Vestergaard P, Mosekilde L, Mortensen LS. Trends in incidence and mortality in the hospital diagnosis of atrial fibrillation or flutter in Denmark, 1980-1999. Int J Cardiol 2005;103:78-84. doi:10.1016/j.ijcard 2004.08.024

4 Colilla S, Crow A, Petkun W, Singer DE, Simon T, Liu X. Estimates of current and future incidence and prevalence of atrial fibrillation in the U.S. adult population. Am / Cardiol 2013;112:1142-7. doi:10.1016/j.amjcard.2013.05.063

5 Piccini JP, Hammill BG, Sinner MF, et al. Incidence and prevalence of atrial fibrillation and associated mortality among Medicare beneficiaries, 1993-2007. Circ Cardiovasc Qual Outcomes 2012;5:85-93. doi:10.1161/ CIRCOUTCOMES.111.962688

6 Lloyd-Jones D, Adams RJ, Brown TM, et al, American Heart Association Statistics Committee and Stroke Statistics Subcommittee. Executive summary: heart disease and stroke statistics--2010 update: a report from the American Heart Association. Circulation 2010;121:948-54. doi:10.1161/CIRCULATIONAHA.109.192666

7 Siontis KC, Gersh BJ, Killian JM, et al. Typical, atypical, and asymptomatic presentations of new-onset atrial fibrillation in the community: Characteristics and prognostic implications. Heart Rhythm 2016;13:1418-24. doi:10.1016/j.hrthm.2016.03.003

8 Boriani G, Laroche C, Diemberger I, et al. Asymptomatic atrial fibrillation: clinical correlates, management, and outcomes in the EORP-AF Pilot General Registry. Am J Med 2015;128:509-18.e2. doi:10.1016/j.amjmed.2014.11.026

9 Kopecky SL, Gersh BJ, McGoon MD, et al. Lone atrial fibrillation in elderly persons: a marker for cardiovascular risk. Arch Intern Med 1999;159:1118-22. doi:10.1001/archinte.159.10.1118

10 Risk factors for stroke and efficacy of antithrombotic therapy in atrial fibrillation. Analysis of pooled data from five randomized controlled trials. Arch Intern Med 1994;154:1449-57. doi:10.1001/ archinte.1994.00420130036007

11 van Latum JC, Koudstaal PJ, Venables GS, van Gijn J, Kappelle LJ, Algra A, European Atrial Fibrillation Trial (EAFT) Study Group. Predictors of major vascular events in patients with a transient ischemic attack or minor ischemic stroke and with nonrheumatic atrial fibrillation. Stroke 1995;26:801-6. doi:10.1161/01.STR.26.5.801

12 Gage BF, Waterman AD, Shannon W, Boechler M, Rich MW, Radford MJ. Validation of clinical classification schemes for predicting stroke: results from the National Registry of Atrial Fibrillation. JAMA 2001;285:2864-70. doi:10.1001/jama.285.22.2864

13 Huizar JF, Ellenbogen KA, Tan AY, Kaszala K. Arrhythmia-Induced Cardiomyopathy: IACC State-of-the-Art Review. J Am Coll Cardiol 2019;73:2328-44. doi:10.1016/j.jacc.2019.02.045
14 Ott A, Breteler MM, de Bruyne MC, van Harskamp F, Grobbee DE, Hofman A. Atrial fibrillation and dementia in a populationbased study. The Rotterdam Study. Stroke 1997;28:316-21. doi:10.1161/01.STR.28.2.316

15 Andersson T, Magnuson A, Bryngelsson IL, et al. All-cause mortality in 272,186 patients hospitalized with incident atrial fibrillation 19952008: a Swedish nationwide long-term case-control study. Eur Heart J 2013;34:1061-7. doi:10.1093/eurheartj/ehs469

16 Chung MK, Eckhardt LL, Chen LY, et al, American Heart Association Electrocardiography and Arrhythmias Committee and Exercise, Cardiac Rehabilitation, and Secondary Prevention Committee of the Council on Clinical Cardiology; Council on Arteriosclerosis, Thrombosis and Vascular Biology; Council on Cardiovascular and Stroke Nursing; and Council on Lifestyle and Cardiometabolic Health. Lifestyle and Risk Factor Modification for Reduction of Atrial Fibrillation: A Scientific Statement From the American Heart Association. Circulation 2020;141:e750-72. doi:10.1161/ CIR.0000000000000748

17 Psaty BM, Manolio TA, Kuller LH, et al. Incidence of and risk factors for atrial fibrillation in older adults. Circulation 1997;96:2455-61. doi:10.1161/01.CIR.96.7.2455

18 Go AS, Hylek EM, Phillips KA, et al. Prevalence of diagnosed atrial fibrillation in adults: national implications for rhythm management and stroke prevention: the AnTicoagulation and Risk Factors in Atrial Fibrillation (ATRIA) Study. JAMA 2001;285:2370-5. doi:10.1001/ jama.285.18.2370

19 Aronow WS, Ahn C, Gutstein H. Prevalence and incidence of cardiovascular disease in 1160 older men and 2464 older women in a long-term health care facility. J Gerontol A Biol Sci Med Sci 2002;57:M45-6. doi:10.1093/gerona/57.1.M45

20 Benjamin EJ, Levy D, Vaziri SM, D’Agostino RB, Belanger AJ, Wolf PA. Independent risk factors for atrial fibrillation in a population-based cohort. The Framingham Heart Study. JAMA 1994:271:840-4. doi:10.1001/jama.1994.03510350050036

21 Zoni-Berisso M, Lercari F, Carazza T, Domenicucci S. Epidemiology of atrial fibrillation: European perspective. Clin Epidemiol 2014;6:213 20. doi:10.2147/CLEP.S47385

22 Nattel S, Burstein B, Dobrev D. Atrial remodeling and atrial fibrillation: mechanisms and implications. Circ Arrhythm Electrophysiol 2008;1:62-73. doi:10.1161/CIRCEP.107.754564

23 Huang HD, Darbar D. Genetic Risk Scores for Atrial Fibrillation: Do They Improve Risk Estimation?Can J Cardiol 2017;33:422-4. doi:10.1016/i.cjca.2016.12.006

24 Fox CS, Parise H, D’Agostino RBSr, et al. Parental atrial fibrillation as a risk factor for atrial fibrillation in offspring. JAMA 2004;291:2851-5. doi:10.1001/jama.291.23.2851

25 Marcus GM, Smith LM, Vittinghoff E, et al. A first-degree family history in lone atrial fibrillation patients. Heart Rhythm 2008;5:826-30 doi:10.1016/j.hrthm.2008.02.016

26 Page RL, Wilkinson WE, Clair WK, McCarthy EA, Pritchett EL. Asymptomatic arrhythmias in patients with symptomatic paroxysmal atrial fibrillation and paroxysmal supraventricular tachycardia. Circulation 1994:89:224-7. doi:10.1161/01.CIR 89.1.224

27 Silberbauer J, Veasey RA, Cheek E, Maddekar N, Sulke N. Electrophysiological characteristics associated with symptoms in pacemaker patients with paroxysmal atrial fibrillation. I Interv Card Electrophysiol 2009;26:31-40. doi:10.1007/s10840-009-9411-x

28 Chugh SS, Blackshear JL, Shen WK, Hammill SC, Gersh BJ. Epidemiology and natural history of atrial fibrillation: clinical implications. J Am Coll Cardiol 2001;37:371-8. doi:10.1016/S07351097(00)01107-4

29 Wijffels MC, Kirchhof C), Dorland R, Allessie MA. Atrial fibrillation begets atrial fibrillation. A study in awake chronically instrumented goats. Circulation 1995;92:1954-68. doi:10.1161/01. CIR.92.7.1954

30 Al-Khatib SM, Wilkinson WE, Sanders LL, McCarthy EA, Pritchett EL. Observations on the transition from intermittent to permanent atrial fibrillation. Am Heart J 2000;140:142-5. doi:10.1067/ mhj.2000.107547

31 Jahangir $\mathrm{A}$, Lee $\mathrm{V}$, Friedman PA, et al. Long-term progression and outcomes with aging in patients with lone atrial fibrillation: a 30 year follow-up study. Circulation 2007;115:3050-6. doi:10.1161/ CIRCULATIONAHA.106.644484

32 Nattel S, Guasch E, Savelieva I, et al. Early management of atrial fibrillation to prevent cardiovascular complications. Eur Heart 2014:35:1448-56. doi:10.1093/eurheartj/ehu028

33 Kirchhof P, Bax J, Blomstrom-Lundquist C, et al. Early and comprehensive management of atrial fibrillation: executive summary of the proceedings from the 2 nd AFNET-EHRA consensus conference 'research perspectives in AF'. Eur Heart / 2009;30:2969-77c. doi:10.1093/eurheartj/ehp235

34 Huxley RR, Lopez FL, Folsom AR, et al. Absolute and attributable risks of atrial fibrillation in relation to optimal and borderline risk factors: the Atherosclerosis Risk in Communities (ARIC) 
study. Circulation 2011;123:1501-8. doi:10.1161/ CIRCULATIONAHA.110.009035

35 Lau DH, Schotten U, Mahajan R, et al. Novel mechanisms in the pathogenesis of atrial fibrillation: practical applications. Eur Heart / 2016;37:1573-81. doi:10.1093/eurheartj/ehv375

36 Middeldorp ME, Ariyaratnam J, Lau D, Sanders P. Lifestyle modifications for treatment of atrial fibrillation. Heart 2020;106:32532. doi:10.1136/heartjnl-2019-315327

37 Pathak RK, Middeldorp ME, Lau DH, et al. Aggressive risk factor reduction study for atrial fibrillation and implications for the outcome of ablation: the ARREST-AF cohort study. J Am Coll Cardiol 2014;64:2222-31. doi:10.1016/j.jacc.2014.09.028

38 Iwasaki YK, Kato T, Xiong F, et al. Atrial fibrillation promotion with long-term repetitive obstructive sleep apnea in a rat model. J Am Coll Cardiol 2014;64:2013-23. doi:10.1016/j.jacc.2014.05.077

39 Abed HS, Samuel CS, Lau DH, et al. Obesity results in progressive atrial structural and electrical remodeling: implications for atrial fibrillation. Heart Rhythm 2013;10:90-100. doi:10.1016/j. hrthm.2012.08.043

40 Guasch E, Benito B, Qi X, et al. Atrial fibrillation promotion by endurance exercise: demonstration and mechanistic exploration in an animal model. J Am Coll Cardiol 2013;62:68-77. doi:10.1016/j. jacc.2013.01.091

41 Kerr CR, Humphries KH, Talajic M, et al. Progression to chronic atrial fibrillation after the initial diagnosis of paroxysmal atrial fibrillation: results from the Canadian Registry of Atrial Fibrillation. Am Heart J 2005;149:489-96. doi:10.1016/j.ahj.2004.09.053

42 de Vos CB, Pisters R, Nieuwlaat R, et al. Progression from paroxysmal to persistent atrial fibrillation clinical correlates and prognosis. / Am Coll Cardiol 2010;55:725-31. doi:10.1016/j.jacc.2009.11.040

43 King S, Fitzgerald A, Bartlett C, et al. The UK NSC recommendation on Atrial Fibrillation screening in adults. 2019. https://legacyscreening. phe.org.uk/atrialfibrillation.

44 Attia ZI, Noseworthy PA, Lopez-Jimenez F, et al. An artificial intelligence-enabled ECG algorithm for the identification of patients with atrial fibrillation during sinus rhythm: a retrospective analysis of outcome prediction. Lancet 2019;394:861-7. doi:10.1016/S01406736(19)31721-0

45 McHutchison JG, Lawitz EJ, Shiffman ML, et al, IDEAL Study Team. Peginterferon alfa-2b or alfa-2a with ribavirin for treatment of hepatitis C infection. N Engl J Med 2009;361:580-93. doi:10.1056/ NEJMoa0808010

46 Kirchhof P, Benussi S, Kotecha D, et al. [2016 ESC Guidelines for the management of atrial fibrillation developed in collaboration with EACTS]. Kardiol Pol 2016;74:1359-469. doi:10.5603/ KP.2016.0172

47 Brieger D, Amerena J, Attia J, et al, NHFA CSANZ Atrial Fibrillation Guideline Working Group. National Heart Foundation of Australia and the Cardiac Society of Australia and New Zealand: Australian Clinical Guidelines for the Diagnosis and Management of Atrial Fibrillation 2018. Heart Lung Circ 2018;27:1209-66. doi:10.1016/j. hlc.2018.06.1043

48 Joung B, Lee JM, Lee KH, et al, KHRS Atrial Fibrillation Guideline Working Group. 2018 Korean Guideline of Atrial Fibrillation Management. Korean Circ J 2018;48:1033-80. doi:10.4070/ kcj.2018.0339

49 Gladstone DJ, Spring M, Dorian P, et al, EMBRACE Investigators and Coordinators. Atrial fibrillation in patients with cryptogenic stroke. N Engl / Med 2014:370:2467-77. doi:10.1056/NEJMoa1311376

50 Engdahl J, Holmén A, Rosenqvist M, Strömberg U. A prospective 5-year follow-up after population-based systematic screening for atrial fibrillation. Europace 2018;20(FI_3):f306-11. doi:10.1093/ europace/euy045

51 Freedman B, Camm J, Calkins H, et al, AF-Screen Collaborators. Screening for Atrial Fibrillation: A Report of the AF-SCREEN International Collaboration. Circulation 2017;135:1851-67. doi:10.1161/CIRCULATIONAHA.116.026693

52 Fitzmaurice DA, Hobbs FD, Jowett S, et al. Screening versus routine practice in detection of atrial fibrillation in patients aged 65 or over: cluster randomised controlled trial. BMJ 2007:335:383. doi:10.1136/bmj.39280.660567.55

53 Svennberg E, Engdahl J, Al-Khalili F, Friberg L, Frykman V, Rosenqvist M. Mass Screening for Untreated Atrial Fibrillation: The STROKESTOP Study. Circulation 2015;131:2176-84. doi:10.1161/ CIRCULATIONAHA.114.014343

54 Halcox JPJ, Wareham K, Cardew A, et al. Assessment of Remote Heart Rhythm Sampling Using the AliveCor Heart Monitor to Screen for Atrial Fibrillation: The REHEARSEAF Study. Circulation 2017;136:1784-94. doi:10.1161/ CIRCULATIONAHA.117.030583

55 Gladstone DJ, Spring M, Dorian P, et al, EMBRACE Investigators and Coordinators. Atrial fibrillation in patients with cryptogenic stroke. N Engl / Med 2014:370:2467-77. doi:10.1056/NEIMoa1311376

56 Lau CP, Siu CW, Yiu KH, Lee KL, Chan YH, Tse HF. Subclinical atrial fibrillation and stroke: insights from continuous monitoring by implanted cardiac electronic devices. Europace 2015;17(Suppl 2):ii40-6. doi:10.1093/europace/euv235

57 Sanna T, Diener HC, Passman RS, et al, CRYSTAL AF Investigators. Cryptogenic stroke and underlying atrial fibrillation. N Engl) Med 2014:370:2478-86. doi:10.1056/NEIMoa1313600

58 Dörr M, Nohturfft V, Brasier N, et al. The WATCH AF Trial: SmartWATCHes for Detection of Atrial Fibrillation. JACC Clin Electrophysiol 2019;5:199-208. doi:10.1016/j.jacep.2018.10.006

59 Perez MV, Mahaffey KW, Hedlin H, et al, Apple Heart Study Investigators. Large-Scale Assessment of a Smartwatch to Identify Atrial Fibrillation. N Engl J Med 2019;381:1909-17. doi:10.1056/ NEJMoa1901183

60 Khurshid S, Healey JS, McIntyre WF, Lubitz SA. Population-Based Screening for Atrial Fibrillation. Circ Res 2020;127:143-54. doi:10.1161/CIRCRESAHA.120.316341

61 Jonas DE, Kahwati LC, Yun JDY, Middleton JC, Coker-Schwimmer M, Asher GN. Screening for Atrial Fibrillation With Electrocardiography: Evidence Report and Systematic Review for the US Preventive Services Task Force. JAMA 2018;320:485-98. doi:10.1001/ jama.2018.4190

62 Chen JY, Zhang AD, Lu HY, Guo J, Wang FF, Li ZC. CHADS2 versus CHA2DS2-VASc score in assessing the stroke and thromboembolism risk stratification in patients with atrial fibrillation: a systematic review and meta-analysis. J Geriatr Cardiol 2013;10:258-66.

63 Lip GY, Nieuwlaat R, Pisters R, Lane DA, Crijns HJ. Refining clinical risk stratification for predicting stroke and thromboembolism in atrial fibrillation using a novel risk factor-based approach: the euro heart survey on atrial fibrillation. Chest 2010;137:263-72. doi:10.1378/ chest.09-1584

64 January CT, Wann LS, Alpert JS, et al, American College of Cardiology/ American Heart Association Task Force on Practice Guidelines. 2014 AHA/ACC/HRS guideline for the management of patients with atrial fibrillation: a report of the American College of Cardiology/American Heart Association Task Force on Practice Guidelines and the Heart Rhythm Society. J Am Coll Cardiol 2014;64:e1-76. doi:10.1016/j. jacc.2014.03.022

65 Olesen JB, Lip GY, Hansen ML, et al. Validation of risk stratification schemes for predicting stroke and thromboembolism in patients with atrial fibrillation: nationwide cohort study. BMJ 2011;342:d124. doi:10.1136/bmi.d12

66 O'Brien EC, Kim S, Hess PL, et al. Effect of the 2014 atrial fibrillation guideline revisions on the proportion of patients recommended for oral anticoagulation. JAMA Intern Med 2015;175:848-50. doi:10.1001/jamainternmed.2015.13

67 Pisters R, Lane DA, Nieuwlaat R, de Vos CB, Crijns HJ, Lip GY. A novel user-friendly score (HAS-BLED) to assess 1-year risk of major bleeding in patients with atrial fibrillation: the Euro Heart Survey. Chest 2010;138:1093-100. doi:10.1378/chest.10-0134

68 Lip GYH, Banerjee A, Lagrenade I, Lane DA, Taillandier S, Fauchier $\mathrm{L}$. Assessing the risk of bleeding in patients with atrial fibrillation: the Loire Valley Atrial Fibrillation project. Circ Arrhythm Electrophysiol 2012;5:941-8. doi:10.1161/CIRCEP.112.972869

69 Apostolakis S, Lane DA, Guo Y, Buller H, Lip GY. Performance of the HEMORR(2)HAGES, ATRIA, and HAS-BLED bleeding risk-prediction scores in patients with atrial fibrillation undergoing anticoagulation: the AMADEUS (evaluating the use of SR34006 compared to warfarin or acenocoumarol in patients with atrial fibrillation) study. J Am Coll Cardiol 2012;60:861-7. doi:10.1016/j.jacc.2012.06.019

70 Roldán V, Marín F, Fernández H, et al. Predictive value of the HASBLED and ATRIA bleeding scores for the risk of serious bleeding in a "real-world" population with atrial fibrillation receiving anticoagulant therapy. Chest 2013;143:179-84. doi:10.1378/chest.12-0608

71 Smith JG, Wieloch M, Koul S, et al. Triple antithrombotic therapy following an acute coronary syndrome: prevalence, outcomes and prognostic utility of the HAS-BLED score. Eurolntervention 2012;8:672-8. doi:10.4244/EIJV8I6A105

72 Omran H, Bauersachs R, Rübenacker S, Goss F, Hammerstingl C. The HAS-BLED score predicts bleedings during bridging of chronic oral anticoagulation. Results from the national multicentre BNK Online bRiDging REgistRy (BORDER). Thromb Haemost 2012;108:65-73. doi:10.1160/TH11-12-0827

73 Camm AJ, Lip GYH, De Caterina R, et al, ESC Committee for Practice Guidelines-CPG, Document Reviewers. 2012 focused update of the ESC Guidelines for the management of atrial fibrillation: an update of the 2010 ESC Guidelines for the management of atrial fibrillation-developed with the special contribution of the European Heart Rhythm Association. Europace 2012;14:1385-413. doi:10.1093/ europace/eus305

74 DeSimone CV, Graff-Radford J, El-Harasis MA, Rabinstein AA, Asirvatham SJ, Holmes DRJr. Cerebral Amyloid Angiopathy: Diagnosis, Clinical Implications, and Management Strategies in Atrial Fibrillation. J Am Coll Cardiol 2017;70:1173-82. doi:10.1016/j. jacc.2017.07.724

75 Charidimou A, Imaizumi T, Moulin S, et al. Brain hemorrhage recurrence, small vessel disease type, and cerebral microbleeds: 
A meta-analysis. Neurology 2017;89:820-9. doi:10.1212/ WNL.0000000000004259

76 Ward R, Ponamgi S, DeSimone CV, et al. Utility of HAS-BLED and $\mathrm{CHA}_{2} \mathrm{DS}_{2}$-VASc Scores Among Patients With Atrial Fibrillation and Imaging Evidence of Cerebral Amyloid Angiopathy. Mayo Clin Proc 2020:95:2090-8 doi:10.1016/j.mayocp.2020.03.034

77 Eckman MH, Rosand J, Knudsen KA, Singer DE, Greenberg SM Can patients be anticoagulated after intracerebral hemorrhage? A decision analysis. Stroke 2003;34:1710-6. doi:10.1161/01. STR.0000078311.18928.16

78 Pokorney SD, Simon DN, Thomas L, et al, Outcomes Registry for Better Informed Treatment of Atrial Fibrillation (ORBIT-AF) Investigators. Patients' time in therapeutic range on warfarin among US patients with atrial fibrillation: Results from ORBIT-AF registry. Am Heart / 2015;170:141-8, 148.e1. doi:10.1016/j.ahj.2015.03.017

79 Zoubida TM, Fatima-Zohra I, Wafaa M, et al. Evaluation of Time in Therapeutic Range in Anticoagulated Patients with Venous Thromboembolism: A Single-Center, Retrospective, Observational Study. Thromb Res 2016;141:S31.

80 van Walraven C, Jennings A, Oake N, Fergusson D, Forster AJ. Effect of study setting on anticoagulation control: a systematic review and metaregression. Chest 2006;129:1155-66. doi:10.1378/ chest.129.5.1155

81 Kearon C, Akl EA, Ornelas J, et al. Antithrombotic Therapy for VTE Disease: CHEST Guideline and Expert Panel Report. Chest 2016;149:315-52. doi:10.1016/j.chest.2015.11.026

82 Ziakas PD, Kourbeti IS, Poulou LS, Vlachogeorgos GS, Mylonakis E. Medicare part D prescribing for direct oral anticoagulants in the United States: Cost, use and the "rubber effect". PLoS One 2018;13:e0198674. doi:10.1371/journal.pone.0198674

83 Zhu J, Alexander GC, Nazarian S, Segal JB, Wu AW. Trends and Variation in Oral Anticoagulant Choice in Patients with Atrial Fibrillation, 2010-2017. Pharmacotherapy 2018;38:907-20. doi:10.1002/phar.2158

84 Camm AJ, Accetta G, Ambrosio G, et al, GARFIELD-AF Investigators. Evolving antithrombotic treatment patterns for patients with newly diagnosed atrial fibrillation. Heart 2017;103:307-14. doi:10.1136/ heartjnl-2016-309832

85 Apenteng PN, Gao H, Hobbs FR, Fitzmaurice DA, UK GARFIELD-AF Investigators and GARFIELD-AF Steering Committee. Temporal trends in antithrombotic treatment of real-world UK patients with newly diagnosed atrial fibrillation: findings from the GARFIELD-AF registry. BMJ Open 2018;8:e018905. doi:10.1136/bmjopen-2017-018905

86 Xian Y, Xu H, O’Brien EC, et al. Clinical Effectiveness of Direct Oral Anticoagulants vs Warfarin in Older Patients With Atrial Fibrillation and Ischemic Stroke: Findings From the Patient-Centered Research Into Outcomes Stroke Patients Prefer and Effectiveness Research (PROSPER) Study. JAMA Neurol 2019;76:1192-202. doi:10.1001/ jamaneurol.2019.2099

87 Larsen TB, Skjøth F, Nielsen PB, Kjældgaard JN, Lip GY. Comparative effectiveness and safety of non-vitamin $\mathrm{K}$ antagonist oral anticoagulants and warfarin in patients with atrial fibrillation: propensity weighted nationwide cohort study. BMJ 2016;353:i3189. doi:10.1136/bmj.i3189

88 Connolly SJ, Ezekowitz MD, Yusuf S, et al, RE-LY Steering Committee and Investigators. Dabigatran versus warfarin in patients with atrial fibrillation. N Engl J Med 2009;361:1139-51. doi:10.1056/ NEJMoa0905561

89 Lip GY, Mitchell SA, Liu X, et al. Relative efficacy and safety of nonVitamin K oral anticoagulants for non-valvular atrial fibrillation: Network meta-analysis comparing apixaban, dabigatran, rivaroxaban and edoxaban in three patient subgroups. Int J Cardiol 2016;204:8894. doi:10.1016/j.ijcard.2015.11.084

90 Giugliano RP, Ruff CT, Braunwald E, et al, ENGAGE AF-TIMI 48 Investigators. Edoxaban versus warfarin in patients with atrial fibrillation. N Engl I Med 2013;369:2093-104. doi:10.1056/ NEJMoa1310907

91 Patel MR, Mahaffey KW, Garg J, et al, ROCKET AF Investigators. Rivaroxaban versus warfarin in nonvalvular atrial fibrillation. N Engl J Med 2011;365:883-91. doi:10.1056/NEJMoa1009638

92 Granger CB, Alexander JH, McMurray JJ, et al, ARISTOTLE Committees and Investigators. Apixaban versus warfarin in patients with atrial fibrillation. N Engl J Med 2011;365:981-92. doi:10.1056/ NEJMoa1107039

93 Chai-Adisaksopha C, Crowther M, Isayama T, Lim W. The impact of bleeding complications in patients receiving target-specific oral anticoagulants: a systematic review and meta-analysis. Blood 2014;124:2450-8. doi:10.1182/blood-2014-07-590323

94 Ruff CT, Giugliano RP, Braunwald E, et al. Comparison of the efficacy and safety of new oral anticoagulants with warfarin in patients with atrial fibrillation: a meta-analysis of randomised trials. Lancet 2014;383:955-62. doi:10.1016/S0140-6736(13)62343-0

95 Chai-Adisaksopha C, Hillis C, Isayama T, Lim W, Iorio A, Crowther M. Mortality outcomes in patients receiving direct oral anticoagulants: a systematic review and meta-analysis of randomized controlled trials. J Thromb Haemost 2015;13:2012-20. doi:10.1111/jth.13139

96 Inohara T, Xian Y, Liang L, et al. Association of Intracerebral Hemorrhage Among Patients Taking Non-Vitamin K Antagonist vs Vitamin K Antagonist Oral Anticoagulants With In-Hospital Mortality. JAMA 2018;319:463-73. doi:10.1001/jama.2017.21917

97 Kakkos SK, Kirkilesis GI, Tsolakis IA. Editor's Choice - efficacy and safety of the new oral anticoagulants dabigatran, rivaroxaban, apixaban, and edoxaban in the treatment and secondary prevention of venous thromboembolism: a systematic review and meta-analysis of phase III trials. Eur J Vasc Endovasc Surg 2014;48:565-75. doi:10.1016/j.ejvs.2014.05.001

98 Raval AN, Cigarroa JE, Chung MK, et al, American Heart Association Clinical Pharmacology Subcommittee of the Acute Cardiac Care and General Cardiology Committee of the Council on Clinical Cardiology; Council on Cardiovascular Disease in the Young; and Council on Quality of Care and Outcomes Research. Management of Patients on Non-Vitamin K Antagonist Oral Anticoagulants in the Acute Care and Periprocedural Setting: A Scientific Statement From the American Heart Association. Circulation 2017;135:e604-33. doi:10.1161/ CIR.0000000000000477

99 Wendelboe AM, Raskob GE. Global Burden of Thrombosis: Epidemiologic Aspects. Circ Res 2016;118:1340-7. doi:10.1161/ CIRCRESAHA.115.306841

100 Pollack CVJr, Reilly PA, Weitz JI. Dabigatran Reversal with Idarucizumab. N Engl/ Med 2017;377:1691-2. doi:10.1056/ NEJMoa1707278

101 Connolly SJ, Gibson CM, Crowther M. Andexanet Alfa for Factor Xa Inhibitor Reversal. N Engl J Med 2016;375:2499-500. doi:10.1056 NEJMoa1607887

102 Eikelboom JW, Connolly SJ, Brueckmann M, et al, RE-ALIGN Investigators. Dabigatran versus warfarin in patients with mechanical heart valves. N Engl J Med 2013;369:1206-14. doi:10.1056 NEJMoa1300615

103 Siontis KC, Yao X, Gersh BJ, Noseworthy PA. Direct Oral Anticoagulants in Patients With Atrial Fibrillation and Valvular Heart Disease Other Than Significant Mitral Stenosis and Mechanical Valves: A Meta-Analysis. Circulation 2017;135:714-6. doi:10.1161/ CIRCULATIONAHA.116.026793

104 Siontis KC, Zhang X, Eckard A, et al. Outcomes Associated With Apixaban Use in Patients With End-Stage Kidney Disease and Atrial Fibrillation in the United States. Circulation 2018;138:1519-29. doi:10.1161/CIRCULATIONAHA.118.035418

105 Chan KE, Edelman ER, Wenger JB, Thadhani RI, Maddux FW. Dabigatran and rivaroxaban use in atrial fibrillation patients on hemodialysis. Circulation 2015;131:972-9. doi:10.1161/ CIRCULATIONAHA.114.014113

106 Noseworthy PA, Yao X, Shah ND, Gersh BJ. Stroke and Bleeding Risks in NOAC- and Warfarin-Treated Patients With Hypertrophic Cardiomyopathy and Atrial Fibrillation. J Am Coll Cardiol 2016;67:3020-1. doi:10.1016/j.jacc.2016.04.026

107 Flaker GC, McGowan DJ, Boechler M, Fortune G, Gage B. Underutilization of antithrombotic therapy in elderly rural patients with atrial fibrillation. Am Heart J 1999;137:307-12. doi:10.1053/ hj.1999.v137.91403

108 Smith NL, Psaty BM, Furberg CD, et al. Temporal trends in the use of anticoagulants among older adults with atrial fibrillation. Arch Intern Med 1999;159:1574-8. doi:10.1001/archinte.159.14.1574

109 Bradley BC, Perdue KS, Tisdel KA, Gilligan DM. Frequency of anticoagulation for atrial fibrillation and reasons for its non-use at a Veterans Affairs medical center. Am J Cardiol 2000;85:568-72. doi:10.1016/S0002-9149(99)00813-9

110 Kalra L, Yu G, Perez I, Lakhani A, Donaldson N. Prospective cohort study to determine if trial efficacy of anticoagulation for stroke prevention in atrial fibrillation translates into clinical effectiveness. BMJ 2000;320:1236-9. doi:10.1136/bmi.320.7244.1236

111 Kakkar AK, Mueller I, Bassand JP, et al, GARFIELD Registry Investigators. Risk profiles and antithrombotic treatment of patients newly diagnosed with atrial fibrillation at risk of stroke: perspectives from the international, observational, prospective GARFIELD registry. PLoS One 2013;8:e63479. doi:10.1371/journal.pone.0063479

112 Hart RG, Pearce LA, Aguilar MI. Meta-analysis: antithrombotic therapy to prevent stroke in patients who have nonvalvular atrial fibrillation. Ann Intern Med 2007;146:857-67. doi:10.7326/0003-4819-14612-200706190-00007

113 Hart RG, Benavente O, McBride R, Pearce LA. Antithrombotic therapy to prevent stroke in patients with atrial fibrillation: a meta-analysis. Ann Intern Med 1999;131:492-501. doi:10.7326/0003-4819-1317-199910050-00003

114 Holmes DR, Reddy VY, Turi ZG, et al, PROTECT AF Investigators. Percutaneous closure of the left atrial appendage versus warfarin therapy for prevention of stroke in patients with atrial fibrillation: a randomised non-inferiority trial. Lancet 2009;374:534-42. doi:10.1016/S0140-6736(09)61343-X 
115 Holmes DRJr, Kar S, Price MJ, et al. Prospective randomized evaluation of the Watchman Left Atrial Appendage Closure device in patients with atrial fibrillation versus long-term warfarin therapy: the PREVAIL trial. J Am Coll Cardiol 2014;64:1-12. doi:10.1016/j. jacc.2014.04.029

116 Reddy VY, Sievert H, Halperin J, et al, PROTECT AF Steering Committee and Investigators. Percutaneous left atrial appendage closure vs warfarin for atrial fibrillation: a randomized clinical trial. IAMA 2014:312:1988-98. doi:10.1001/jama.2014.15192

117 Reddy VY, Gibson DN, Kar S, et al. Post-approval U.S. experience with left atrial appendage closure for stroke prevention in atrial fibrillation. J Am Coll Cardiol 2017;69:253-61. doi:10.1016/j.jacc.2016.10.010

118 Reddy VY, Möbius-Winkler S, Miller MA, et al. Left atrial appendage closure with the Watchman device in patients with a contraindication for oral anticoagulation: the ASAP study (ASA Plavix Feasibility Study With Watchman Left Atrial Appendage Closure Technology). J Am Coll Cardiol 2013;61:2551-6. doi:10.1016/j.jacc.2013.03.035

119 Holmes DRJr, Doshi SK, Kar S, et al. Left atrial appendage closure as an alternative to warfarin for stroke prevention in atrial fibrillation: a patient-level meta-analysis. J Am Coll Cardiol 2015;65:2614-23. doi:10.1016/j.jacc.2015.04.025

120 Piazza G, Karipineni N, Goldberg HS, Jenkins KL, Goldhaber SZ. Underutilization of Anticoagulation for Stroke Prevention in Atrial Fibrillation. J Am Coll Cardiol 2016;67:2444-6. doi:10.1016/j. jacc.2016.03.515

121 Xian Y, O'Brien EC, Liang L, et al. Association of Preceding Antithrombotic Treatment With Acute Ischemic Stroke Severity and In-Hospital Outcomes Among Patients With Atrial Fibrillation. JAMA 2017:317:1057-67. doi:10.1001/jama.2017.1371

122 Yao X, Abraham NS, Alexander GC, et al. Effect of Adherence to Oral Anticoagulants on Risk of Stroke and Major Bleeding Among Patients With Atrial Fibrillation. J Am Heart Assoc 2016;5:e003074. doi:10.1161/JAHA.115.003074

123 Siontis KC, Montori VM, Noseworthy PA. Multimodal Interventions to Increase Anticoagulant Utilization in Atrial Fibrillation: Futile Without Patient Engagement?Circ Cardiovasc Qual Outcomes 2020;13:e006418. doi:10.1161/ CIRCOUTCOMES.120.006418

124 Paquette M, Witt DM, Holbrook A, et al. A systematic review and meta-analysis of supplemental education in patients treated with oral anticoagulation. Blood Adv 2019;3:1638-46. doi:10.1182/ bloodadvances. 2019000067

125 Hohnloser SH, Kuck KH, Lilienthal J. Rhythm or rate control in atrial fibrillation--Pharmacological Intervention in Atrial Fibrillation (PIAF): a randomised trial. Lancet 2000;356:1789-94. doi:10.1016/S01406736(00)03230-X

126 Wyse DG, Waldo AL, DiMarco JP, et al, Atrial Fibrillation Follow-up Investigation of Rhythm Management (AFFIRM) Investigators. A comparison of rate control and rhythm control in patients with atrial fibrillation. N Engl J Med 2002;347:1825-33. doi:10.1056 NEJMoa021328

127 Prabhu S, Taylor AJ, Costello BT, et al. Catheter Ablation Versus Medical Rate Control in Atrial Fibrillation and Systolic Dysfunction: The CAMERA-MRI Study. J Am Coll Cardiol 2017;70:1949-61. doi:10.1016/j.jacc.2017.08.041

128 Gopinathannair R, Etheridge SP, Marchlinski FE, Spinale FG, Lakkireddy D, Olshansky B. Arrhythmia-Induced Cardiomyopathies: Mechanisms, Recognition, and Management. J Am Coll Cardiol 2015;66:1714-28. doi:10.1016/j.jacc.2015.08.038

129 Erdmann E. Safety and tolerability of beta-blockers: prejudices \& reality. Indian Heart J 2010;62:132-5.

130 Kerr C, Boone J, Connolly S, et al. Follow-up of atrial fibrillation: The initial experience of the Canadian Registry of Atrial Fibrillation. Eur Heart J 1996;17(Suppl C):48-51. doi:10.1093/eurheartj/17. suppl_C.48

131 Kirchhof P, Camm Al, Goette A, et al, EAST-AFNET 4 Trial Investigators. Early Rhythm-Control Therapy in Patients with Atrial Fibrillation. N Engl J Med 2020;383:1305-16. doi:10.1056/NEJMoa2019422

132 Chimienti M, Cullen MTJr, Casadei G. Safety of long-term flecainide and propafenone in the management of patients with symptomatic paroxysmal atrial fibrillation: report from the Flecainide and Propafenone Italian Study Investigators. Am J Cardiol 1996:77:60A-75A doi:10.1016/S0002-9149(97)89119-9

133 Echt DS, Liebson PR, Mitchell LB, et al. Mortality and morbidity in patients receiving encainide, flecainide, or placebo. The Cardiac Arrhythmia Suppression Trial. N Engl J Med 1991;324:781-8. doi:10.1056/NEIM199103213241201

134 Benditt DG, Williams JH, Jin J, et al. Maintenance of sinus rhythm with oral d,l-sotalol therapy in patients with symptomatic atrial fibrillation and/or atrial flutter. d,l-Sotalol Atrial Fibrillation/Flutter Study Group. Am J Cardiol 1999;84:270-7. doi:10.1016/S00029149(99)00275-1

135 Singh S, Zoble RG, Yellen L, et al. Efficacy and safety of oral dofetilide in converting to and maintaining sinus rhythm in patients with chronic atrial fibrillation or atrial flutter: the symptomatic atrial fibrillation investigative research on dofetilide (SAFIRE-D) study. Circulation 2000:102:2385-90. doi:10.1161/01.CIR.102.19.2385

136 Roy D, Talajic M, Dorian P, et al, Canadian Trial of Atrial Fibrillation Investigators. Amiodarone to prevent recurrence of atrial fibrillation. N Engl J Med 2000;342:913-20. doi:10.1056/ NEJM200003303421302

137 Goldschlager N, Epstein AE, Naccarelli G, Olshansky B, Singh B. Practical guidelines for clinicians who treat patients with amiodarone. Practice Guidelines Subcommittee, North American Society of Pacing and Electrophysiology. Arch Intern Med 2000;160:1741-8. doi:10.1001/archinte.160.12.1741

138 Jaïs P, Haïssaguerre M, Shah DC, et al. A focal source of atrial fibrillation treated by discrete radiofrequency ablation. Circulation 1997;95:572-6. doi:10.1161/01.CIR.95.3.572

139 Haïssaguerre M, Jaïs P, Shah DC, et al. Spontaneous initiation of atrial fibrillation by ectopic beats originating in the pulmonary veins. N Engl J Med 1998;339:659-66. doi:10.1056/NEJM199809033391003

140 Calkins H, Kuck KH, Cappato R, et al, Heart Rhythm Society Task Force on Catheter and Surgical Ablation of Atrial Fibrillation. 2012 HRS/EHRA/ECAS expert consensus statement on catheter and surgical ablation of atrial fibrillation: recommendations for patient selection, procedural techniques, patient management and followup, definitions, endpoints, and research trial design: a report of the Heart Rhythm Society (HRS) Task Force on Catheter and Surgical Ablation of Atrial Fibrillation. Developed in partnership with the European Heart Rhythm Association (EHRA), a registered branch of the European Society of Cardiology (ESC) and the European Cardiac Arrhythmia Society (ECAS); and in collaboration with the American College of Cardiology (ACC), American Heart Association (AHA), the Asia Pacific Heart Rhythm Society (APHRS), and the Society of Thoracic Surgeons (STS). Endorsed by the governing bodies of the American College of Cardiology Foundation, the American Heart Association, the European Cardiac Arrhythmia Society, the European Heart Rhythm Association, the Society of Thoracic Surgeons, the Asia Pacific Heart Rhythm Society, and the Heart Rhythm Society. Heart Rhythm 2012;9:632-696.e21. doi:10.1016/j.hrthm.2011.12.016

141 Verma A, Jiang CY, Betts TR, et al, STAR AF II Investigators. Approaches to catheter ablation for persistent atrial fibrillation. $N$ Engl I Med 2015:372:1812-22. doi:10.1056/NEIMoa1408288

142 Katritsis DG, Giazitzoglou E, Zografos T, Pokushalov E, Po SS, Camm AJ. Rapid pulmonary vein isolation combined with autonomic ganglia modification: a randomized study. Heart Rhythm 2011;8:672-8. doi:10.1016/j.hrthm.2010.12.047

143 Mazur P. Cryobiology: the freezing of biological systems. Science 1970;168:939-49. doi:10.1126/science.168.3934.939

144 Takamatsu H, Zawlodzka S. Contribution of extracellular ice formation and the solution effects to the freezing injury of PC-3 cells suspended in $\mathrm{NaCl}$ solutions. Cryobiology 2006;53:1-11. doi:10.1016/j. cryobiol.2006.03.005

145 Gill W, Da Costa J, Fraser J. The control and predictability of a cryolesion. Cryobiology 1970;6:347-53. doi:10.1016/S00112240(70)80089-X

146 Packer DL, Kowal RC, Wheelan KR, et al, STOP AF Cryoablation Investigators. Cryoballoon ablation of pulmonary veins for paroxysmal atrial fibrillation: first results of the North American Arctic Front (STOP AF) pivotal trial. J Am Coll Cardiol 2013;61:1713-23. doi:10.1016/j.jacc.2012.11.064

147 Kuck KH, Fürnkranz A, Chun KR, et al, FIRE AND ICE Investigators. Cryoballoon or radiofrequency ablation for symptomatic paroxysmal atrial fibrillation: reintervention, rehospitalization, and quality-of-life outcomes in the FIRE AND ICE trial. Eur Heart) 2016;37:2858-65. doi:10.1093/eurhearti/ehw285

148 Kautzner J, Neuzil P, Lambert H, et al. EFFICAS II: optimization of catheter contact force improves outcome of pulmonary vein isolation for paroxysmal atrial fibrillation. Europace 2015;17:1229-35. doi:10.1093/europace/euv057

149 Aryana A, Singh SM, Kowalski M, et al. Acute and Long-Term Outcomes of Catheter Ablation of Atrial Fibrillation Using the SecondGeneration Cryoballoon versus Open-Irrigated Radiofrequency: A Multicenter Experience. J Cardiovasc Electrophysiol 2015;26:832-9. doi:10.1111/jce.12695

150 Esler MD, Krum H, Sobotka PA, Schlaich MP Schmieder RE, Böhm M, Symplicity HTN-2 Investigators. Renal sympathetic denervation in patients with treatment-resistant hypertension (The Symplicity HTN-2 Trial): a randomised controlled trial. Lancet 2010;376:1903-9. doi:10.1016/S0140-6736(10)62039-9

151 Hering D, Lambert EA, Marusic P, et al. Substantial reduction in single sympathetic nerve firing after renal denervation in patients with resistant hypertension. Hypertension 2013;61:457-64. doi:10.1161/HYPERTENSIONAHA.111.00194

152 Steinberg JS, Shabanov V, Ponomarev D, et al. Effect of Renal Denervation and Catheter Ablation vs Catheter Ablation Alone on Atrial Fibrillation Recurrence Among Patients With Paroxysmal Atrial 
Fibrillation and Hypertension: The ERADICATE-AF Randomized Clinical Trial. JAMA 2020;323:248-55. doi:10.1001/jama.2019.21187

153 Poole JE, Bahnson TD, Monahan KH, et al, CABANA Investigators and ECG Rhythm Core Lab. Recurrence of Atrial Fibrillation After Catheter Ablation or Antiarrhythmic Drug Therapy in the CABANA Trial. . Am Coll Cardiol 2020;75:3105-18. doi:10.1016/j.jacc.2020.04.065

154 Andrade JG, Champagne J, Dubuc M, et al, CIRCA-DOSE Study Investigators. Cryoballoon or Radiofrequency Ablation for Atrial Fibrillation Assessed by Continuous Monitoring: A Randomized Clinical Trial. Circulation 2019;140:1779-88. doi:10.1161/ CIRCULATIONAHA.119.042622

155 Packer DL, Mark DB, Robb RA, et al, CABANA Investigators. Effect of Catheter Ablation vs Antiarrhythmic Drug Therapy on Mortality, Stroke, Bleeding, and Cardiac Arrest Among Patients With Atrial Fibrillation: The CABANA Randomized Clinical Trial. IAMA 2019:321:1261-74 doi:10.1001/jama.2019.0693

156 Siontis KC, loannidis JPA, Katritsis GD, et al. Radiofrequency ablation versus antiarrhythmic drug therapy for atrial fibrillation: meta-analysis of quality of life, morbidity, and mortality. JACC Clin Electrophysiol 2016;2:170-80. doi:10.1016/j.jacep.2015.10.003

157 Wazni OM, Marrouche NF, Martin DO, et al. Radiofrequency ablation vs antiarrhythmic drugs as first-line treatment of symptomatic atrial fibrillation: a randomized trial. JAMA 2005;293:2634-40. doi:10.1001/jama.293.21.2634

158 Morillo CA, Verma A, Connolly SJ, et al, RAAFT-2 Investigators. Radiofrequency ablation vs antiarrhythmic drugs as first-line treatment of paroxysmal atrial fibrillation (RAAFT-2): a randomized trial. JAMA 2014;311:692-700. doi:10.1001/jama.2014.467

159 Jons C, Hansen PS, Johannessen A, et al, MANTRA-PAF Investigators. The Medical ANtiarrhythmic Treatment or Radiofrequency Ablation in Paroxysmal Atrial Fibrillation (MANTRA-PAF) trial: clinical rationale, study design, and implementation. Europace 2009;11:917-23. doi:10.1093/europace/eup122

160 Barnes GD, Nallamothu BK, Sales AE, Froehlich JB. Reimagining Anticoagulation Clinics in the Era of Direct Oral Anticoagulants. Circ Cardiovasc Qual Outcomes 2016;9:182-5. doi:10.1161/ CIRCOUTCOMES.115.002366

161 Marrouche NF, Brachmann J, Andresen D, et al, CASTLE-AF Investigators. Catheter ablation for atrial fibrillation with heart failure. N Engl J Med 2018;378:417-27. doi:10.1056/NEJMoa1707855

162 Chew DS, Black-Maier E, Loring Z, et al. Diagnosis-to-Ablation Time and Recurrence of Atrial Fibrillation Following Catheter Ablation: A Systematic Review and Meta-Analysis of Observational Studies. Circ Arrhythm Electrophysiol 2020;13:e008128. doi:10.1161/ CIRCEP.119.008128

163 van den Dries CJ, van Doorn S, Rutten FH, et al. Integrated management of atrial fibrillation in primary care: results of the ALL-IN cluster randomized trial. Eur Heart J 2020;41:2836-44. doi:10.1093/eurheartj/ehaa055

164 Gallagher C, Elliott AD, Wong CX, et al. Integrated care in atrial fibrillation: a systematic review and meta-analysis. Heart 2017;103:1947-53. doi:10.1136/heartjnl-2016-310952

165 Kirchhof P, Benussi S, Kotecha D, et al. 2016 ESC Guidelines for the Management of Atrial Fibrillation Developed in Collaboration With EACTS. Rev Esp Cardiol (Engl Ed) 2017;70:50. doi:10.1016/j. rec.2016.11.033
166 Voskoboinik A, Kalman JM, De Silva A, et al. Alcohol Abstinence in Drinkers with Atrial Fibrillation. N Engl J Med 2020;382:20-8. doi:10.1056/NEJMoa1817591

167 Bardy GH, Lee KL, Mark DB, et al, Sudden Cardiac Death in Heart Failure Trial (SCD-HeFT) Investigators. Amiodarone or an implantable cardioverter-defibrillator for congestive heart failure. N Engl] Med 2005;352:225-37. doi:10.1056/NEJMoa043399

168 Siddoway LA. Amiodarone: guidelines for use and monitoring. Am Fam Physician 2003;68:2189-96.

169 Proietti M, Romiti GF, Olshansky B, Lane DA, Lip GYH. Comprehensive Management With the ABC (Atrial Fibrillation Better Care) Pathway in Clinically Complex Patients With Atrial Fibrillation: A Post Hoc Ancillary Analysis From the AFFIRM Trial. J Am Heart Assoc 2020;9:e014932. doi:10.1161/JAHA.119.014932

170 Guo Y, Lane DA, Wang L, et al, mAF-App II Trial Investigators. Mobile Health Technology to Improve Care for Patients With Atrial Fibrillation. J Am Coll Cardiol 2020;75:1523-34. doi:10.1016/j. jacc.2020.01.052

171 Zeballos-Palacios CL, Hargraves IG, Noseworthy PA, et al, Shared Decision Making for Atrial Fibrillation (SDM4AFib) Trial Investigators. Developing a Conversation Aid to Support Shared Decision Making: Reflections on Designing Anticoagulation Choice. Mayo Clin Proc 2019;94:686-96. doi:10.1016/j.mayocp.2018.08.030

172 Barry MJ, Edgman-Levitan S. Shared decision making--pinnacle of patient-centered care. N Engl J Med 2012;366:780-1. doi:10.1056/ NEJMp1109283

173 Institute of Medicine (US) Committee on Quality of Health Care in America. Crossing the Quality Chasm: A New Health System for the 21st Century. National Academies Press, 2001.

174 Hernández Madrid A, Potpara TS, Dagres N, et al. Differences in attitude, education, and knowledge about oral anticoagulation therapy among patients with atrial fibrillation in Europe: result of a self-assessment patient survey conducted by the European Heart Rhythm Association. Europace 2016;18:463-7. doi:10.1093/ europace/euv448

175 Frankel DS, Parker SE, Rosenfeld LE, Gorelick PB. HRS/NSA 2014 survey of atrial fibrillation and stroke: Gaps in knowledge and perspective, opportunities for improvement. Heart Rhythm 2015;12:e105-13. doi:10.1016/j.hrthm.2015.04.039

176 Camm AJ, Lip GY, De Caterina R, et al, ESC Committee for Practice Guidelines (CPG). 2012 focused update of the ESC Guidelines for the management of atrial fibrillation: an update of the 2010 ESC Guidelines for the management of atrial fibrillation. Developed with the special contribution of the European Heart Rhythm Association. Eur Heart J 2012;33:2719-47. doi:10.1093/eurheartj/ehs253

177 Reddy VY, Neuzil P, Koruth JS, et al. Pulsed Field Ablation for Pulmonary Vein Isolation in Atrial Fibrillation. J Am Coll Cardiol 2019;74:315-26. doi:10.1016/j.jacc.2019.04.021

178 Reddy VY, Anter E, Rackauskas G, et al. Lattice-Tip Focal Ablation Catheter That Toggles Between Radiofrequency and Pulsed Field Energy to Treat Atrial Fibrillation: A First-in-Human Trial. Circ Arrhythm Electrophysiol 2020;13:e008718. doi:10.1161/ CIRCEP.120.008718

179 Cuculich PS, Schill MR, Kashani R, et al. Noninvasive Cardiac Radiation for Ablation of Ventricular Tachycardia. N EnglJ Med 2017;377:2325-36. doi:10.1056/NEJMoa1613773 